Portland State University

PDXScholar

1992

\title{
Perceptions of teacher and student roles : views of Japanese businessmen
}

John Walter Armbrust

Portland State University

Follow this and additional works at: https://pdxscholar.library.pdx.edu/open_access_etds

Part of the Applied Linguistics Commons

Let us know how access to this document benefits you.

\section{Recommended Citation}

Armbrust, John Walter, "Perceptions of teacher and student roles : views of Japanese businessmen" (1992). Dissertations and Theses. Paper 4273.

https://doi.org/10.15760/etd.6157

This Thesis is brought to you for free and open access. It has been accepted for inclusion in Dissertations and Theses by an authorized administrator of PDXScholar. Please contact us if we can make this document more accessible: pdxscholar@pdx.edu. 
AN ABSTRACT OF THE THESIS OF John Walter Armbrust for the Master of Arts in TESOL presented on November 6, 1992.

Title: Perceptions of Teacher and Student Roles: Views of Japanese Businessmen.

APPROVED BY THE MEMBERS OF THE THESIS COMMITTEE:
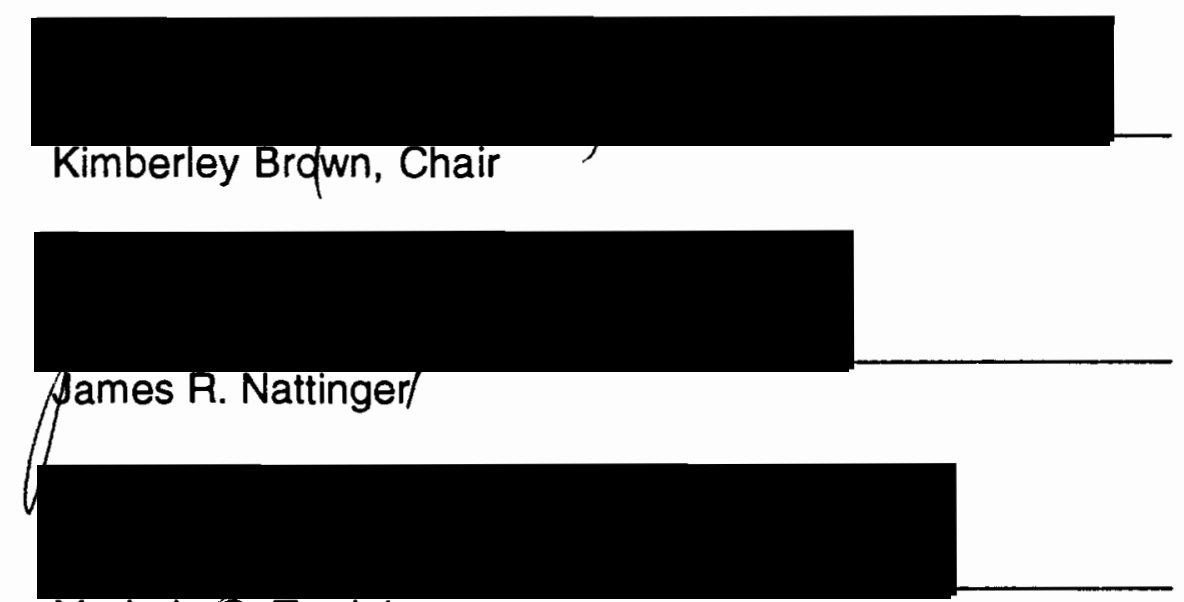
Marjorie's. Terdal

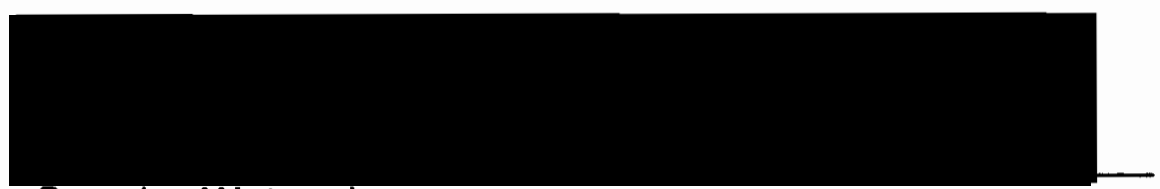

Suwako Watanabe

Research provides a vast amount of information detailing the learning styles and preferences of learners and the influence of one's culture on that individual's perceptions of the world. Little of that research, however, has been applied to studying the effects of culture on the learner's perceptions of teacher and student roles, specifically in the area of second language learning. What is available often appears in the form of anecdotal descriptions of teaching and 
learning experiences abroad. A possible reason for the lack of investigation of student views in this area has been the absence of an adequate measuring device with which to gauge the responses of potential informants.

This study proposes the use of a survey form developed from data in an empirical study of cross-cultural differences among societies by Geert Hofstede. That quantitative study of individuals in over fifty countries served as the basis for Hofstede's Four-Dimensional Model of Cultural Differences, the framework for cross-cultural analysis employed in this qualitative inquiry.

Five Japanese executives studying ESL in an American university served as the informants, offering their perceptions of cultural differences in teacher/student roles, classroom interaction patterns, and learning strategies.

Examination of the field notes from the open-ended interview sessions revealed certain themes recurring through the course of the discussions. They included: student views regarding individual versus group behavior and responsibilities in the classroom, the status of creativity and order in language learning, and the role of examinations in the Japanese educational system.

Results of this investigation offered support for Hofstede's contention that there are culturally-based assumptions which color students' perceptions of both learners' and teachers' roles in the classroom. Each of Hofstede's predictions about Japanese culture were not completely endorsed by this group of respondents, however. The most obvious area of disagreement was found in views relating to what Hofstede termed "masculine" attributes of culture, an area in which Japan was designated the most masculine of all cultures surveyed.

The study also served to validate the use of this survey form as a useful tool in investigating attitudes, beliefs, and behaviors in the second language classroom while offering a reliable method of enhancing and expanding upon 
the empirical findings of Hofstede. It suggests a plausible format for researchers and educators wishing to explore interactions and relationships in a variety of learning environments. 
PERCEPTIONS OF TEACHER AND STUDENT ROLES:

VIEWS OF JAPANESE BUSINESSMEN

\author{
by \\ JOHN WALTER ARMBRUST
}

A thesis submitted in partial fulfillment of the requirements of the degree of

\title{
MASTER OF ARTS \\ in \\ TESOL
}

Portland State University

1992 
TO THE OFFICE OF GRADUATE STUDIES:

The members of the Committee approve the thesis of John Walter Armbrust presented on November 6, 1992.

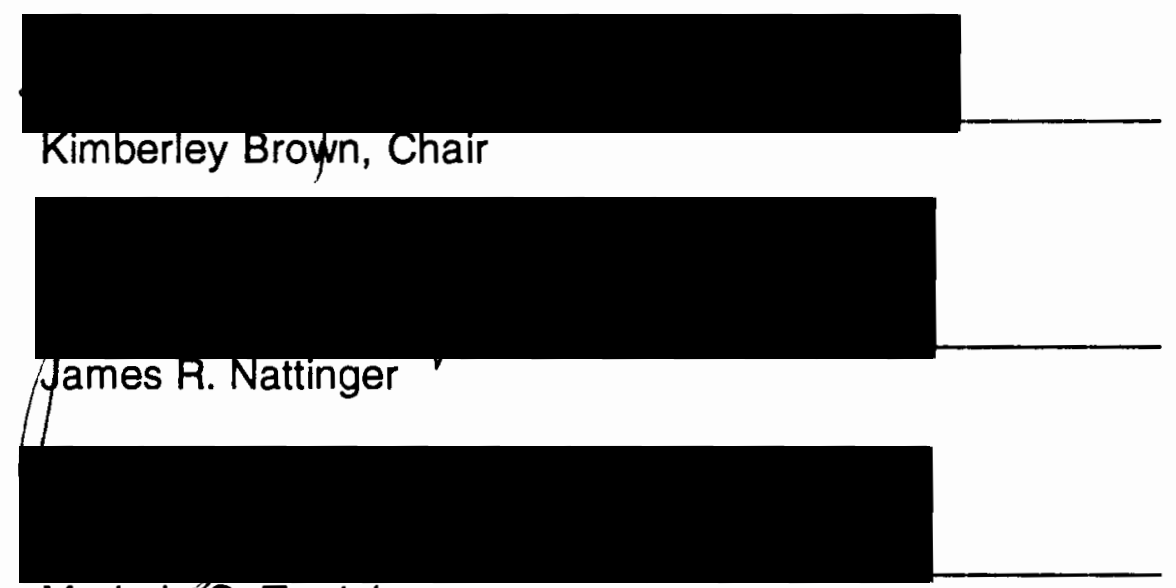

Marjorie's. Terdal

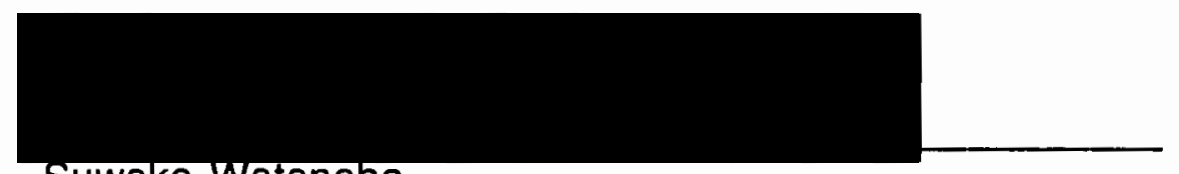

Suwako Watanabe

\section{APPROVED:}

pames R. Nattinger, Unalr, Departinent of Applied Linguistics 1

Roy W. Koch, Vice Provost for Graduate Studies and Research 
" . . . what constitutes the dignity of a craft is that it creates a fellowship, that it binds men together and fashions for them a common language. For there is but one veritable problem - the problem of human relations."

- Antoine de Saint-Exupery, Wind, Sand and Stars 


\section{PREFACE AND ACKNOWLEDGEMENTS}

Ask a roomful of people to define "teacher" or "student" and you are likely to get as many different interpretations as there are individuals in the room. Expand the group of respondents to include individuals from different cultures, and the definitions are likely to be even more diverse.

People naturally frame their reactions to and interpretations of people and events around them in forms that reflect their cultural assumptions about the world. For many people, the world that they perceive is so real for them that they do not stop to think that it may be based upon or composed of a set of assumptions unique to their frame of reference. It is not unusual, then, to expect that individual perceptions of classroom roles for both teachers and students will reflect a wide variety of beliefs and values.

This study deals with some of those perceptions, the views of five Japanese businessmen, regarding their impressions of what teachers and learners are and perhaps should be. They reflect culturally-based ideas that were both predictable and unpredictable. For me, they have helped redefine my personal views on teaching and learning languages. They are the products of a qualitative investigation that began with questions arising from teaching assignments at home and abroad but brought to fruition through the suggestions and contributions of a number of people.

A germ of the seed in this process of discovery was planted by Jim Nattinger, who helped me understand the relative nature of cultural values 
while also presenting me with a cogent role model of a professional educator. His encouragement and guidance are greatly appreciated

The process was further nurtured through the direction and support of Marjorie Terdal, who first introduced me to the concept of ethnographic study and who regularly encouraged me to try my hand at pursuing qualitative research. For her selfless gifts of time and concern and for her invaluable modeling of instructional expertise, I am particularly grateful.

By far the largest debt of gratitude is owed to Kim Brown, who introduced me to the studies of Hofstede and Nelson, and who constantly provided me with the direction and support I needed to complete this project. Her ability to focus on both immediate tasks and long-range goals was extremely useful in all phases of crafting this study. For her conscientious mentoring in this "apprenticeship", I am especially thankful, and for her personal interest, friendship, and encouragement, I am truly grateful.

A special note of thanks is also due to Gayle Nelson for her generosity in sharing the survey form which she developed. It provided a well-organized instrument for evoking and examining the perceptions of the informants in this study. I look forward to seeing the published results of her study using the same survey form.

Personal thanks are also extended to several individuals, including my long-time friend, Carmen, who helped keep in perspective the advantages of completing this project; to my sister, Ginny, for her personal acceptance and support over the years; to my parents for their continued encouragement and support; and to my closest friend, Tom, who died from AIDS in the past year, but who left me with a healthier appreciation for some of the personal aspects of this teaching craft. 
Finally, I would like to thank the five Japanese executives who gave so freely of their time throughout the course of this study. Their interest and contributions made a task which at times seem formidable and endless one that became a pleasure to pursue. I am very grateful to all of them for their high level of enthusiasm and participation. 
TABLE OF CONTENTS

PAGE

PREFACE AND ACKNOWLEDGEMENTS . . . . . . . . . . . . iv LIST OF TABLES . . . . . . . . . . . . . . . . . ix

CHAPTER

I INTRODUCTION . . . . . . . . . . . . . . . 1

II REVIEW OF LITERATURE . . . . . . . . . . . . . . . . . . 4

The Role of Culture in Second-Language Learning . . 4

The Role of the Language Learner's Culture . . . . . 7

Japanese and American Cultural Values . . . . . . . 9

The Role of Culture in Perceptions of Teacher/Student Roles . . . . . . . . . . . . . . 12

III METHODOLOGY . . . . . . . . . . . . . 21

Subjects . . . . . . . . . . . . . 21

Procedure . . . . . . . . . . . . . . 25

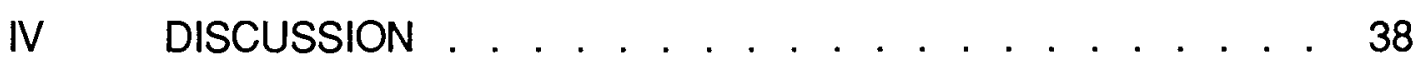

Individual Versus Group Behavior and Responsibilities 40

Creativity Versus Order in Language Learning . . . . 55

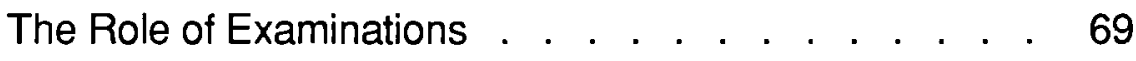

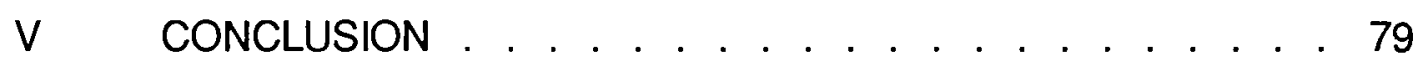

Summary of Findings . . . . . . . . . . . . . . . . . 79 
Limitations of the Study . . . . . . . . . . . . . . 85

Suggestions for Further Research . . . . . . . . . 87

Implications and Recommendations for Teaching . . 89

REFERENCES . . . . . . . . . . . . . . . . . . . . . . . . . . 94 APPENDICES

A CROSS-CULTURAL EDUCATION SURVEY. . . . . 100

B INFORMED CONSENT FORM ......... . 105

C INDIVIDUAL COUNTRY SCORES: HOFSTEDE'S

CROSS-CULTURAL DIFFERENCES . . . . . . . 107 


\section{LIST OF TABLES}

TABLE

PAGE

I Participant Responses on Survey Items - Part A . . . . . . . 42

II $\quad$ Participant Responses on Survey Items - Part B . . . . . . . 57 


\section{CHAPTER I}

\section{INTRODUCTION}

The craft of teaching is one that binds together student and teacher in a fabric of complex patterns and weaves. In the studio-classroom of English as a Second Language, the strands of diverse cultures are interwoven to produce interplays of elaborate hue and texture. Classroom interactions involving culturally-based values, beliefs, and assumptions intersect, creating situations that are sometimes predictable, sometimes problematic, and oftentimes unique. When the participants in these interpersonal exchanges come from cultures as divergent as Japan and the United States, the process of fashioning a common language may indeed be, as de Saint-Exupery proposes, one of human relations.

This thesis examines perceptions of five Japanese businessmen regarding teacher and student roles in those classroom interaction patterns. It uses a cross-cultural education survey designed by Gayle Nelson, (Appendix A), and adapted from Geert Hofstede's (1986) tables of differences in teacher/student and student/student interactions, to study the participants' views on educational roles, classroom interaction patterns, and learning strategies in the second language classroom. The survey was used in a series of openended interviews to elicit responses from five Japanese executives recounting individual experiences and perceptions in learning a second language. The respondents were all students at a small private college in the Pacific 
Northwest, taking part in five and six-week programs of language study aimed at improving their communicative skills in English.

Analysis of the field notes from interview sessions conducted with the five informants revealed several themes that recurred throughout the course of the discussions. The themes include: individual versus group behavior and responsibilities, creativity versus order in language learning, and the role of examinations in the Japanese educational system. They serve as the framework for the discussion in this qualitative study of teacher and student roles in the second language classroom, and they address the following research questions: what role does cultural variability play in student perceptions of classroom goals and responsibilities; how do societal norms regarding group membership affect individual participation in the classroom; is creativity a culturally relative notion, and what is its relation to order in language learning; and how do examinations influence curricular, methodological, and personal goals for education in Japan?

The participants' responses to the survey questions provided the data for this investigation, which were then compared to Hofstede's (1986) predictions about Japanese culture as it relates to educational roles. Those predictions were based upon his prior empirical studies of cultural differences among societies, the data from which had earlier led to the formation of his FourDimensional Model of Cultural Differences (1980). Discussion of the informants' comments in this particular study are also analyzed with reference to the four dimensions of Hofstede's model: power distance, uncertainty avoidance, individualism/collectivism, and masculinity/feminity.

Throughout this study the voices of five Japanese businessmen recall their experiences as students in the Japanese educational system and how 
those events colored their perspectives on teaching and learning. Their voices are interwoven among the themes of this investigation, adding texture and hue to the fabric of the discussions that examine student perceptions of the roles involved in the craft of teaching a second language. 


\section{CHAPTER II}

\section{REVIEW OF LITERATURE}

A good deal of research is available on the importance of culture in the learning of a second language, yet very little exists on the role of the language learner's own culture in that process. Most of it has to do with the ability of the language learner to adapt to and understand the target culture, and in the case of international students studying at schools in the United States, that has meant American culture. Likewise, the volume of material regarding cultural differences among societies is quite large, including much information on the differences between Japanese and American cultures. Little of that research, however, has been applied to the influence of culture on the individual roles of the teacher and learner in the acquisition of a second language. Each of these areas will be discussed with the goal of narrowing the scope of this study to the effects of a language learner's culture on the perception of student and teacher roles in ESL study.

\section{THE ROLE OF CULTURE IN SECOND-LANGUAGE LEARNING}

\section{Paulston (1975) and Saville-Troike (1976) define the EFL/ESL} classroom as a potential setting where students' cultural values and ideas about language learning may differ dramatically from those of the classroom teacher or the curriculum designer. Developing this idea further, Byrd (1986) points out that culturally-based student fears and uncertainties coupled with narrowly-defined goals may combine with a teacher's limited exposure in cross- 
cultural training to produce barriers to cultural empathy and linguistic competence. In essence, she maintains that real or imagined student apprehension, based on past political and educational experiences, can negatively affect student performance in the second language classroom. Moreover, student goals that are extremely limited, and perhaps culturally induced, such as studying to pass the Test of English as a Foreign Language (TOEFL) or simply to build a large technical vocabulary in a field of interest, may also impede a student's development toward linguistic competence. When either or both of these are present in a classroom headed by an instructor with little or no training in cross-cultural empathy, the author predicts results that can reduce the ease and extent to which a second language is mastered.

Other researchers (Bailey, 1983; Brown, 1980; Fillmore, 1982; Schumann \& Schumann, 1977; and Tinkham, 1989) note that aspects of cultural distance and assimilation may affect learner attitudes toward language classes and teachers in addition to altering learner feelings of security and selfconfidence. Within this context, they explore socio-cultural variables such as competitiveness, anxiety, and cultural bias, elements that affect classroom performance. At the same time, they emphasize the teacher's need to be aware of and adapt to student differences.

The topic of social distance is treated by Brown (1987) in his discussion of factors which influence the acquisition of a second language. He describes it as the dissimilarity between two cultures, a rather subjective phenomenon that seems to defy actual definition, like other psychological constructs such as empathy and self-esteem, but one which is capable of being understood intuitively. He maintains that there is an "optimal distance" that combines with "optimal cognitive and affective tension" to produce a healthy "pressure" that 
promotes language learning. He calls this the "critical period", and he maintains that it varies from one learner to another (pp. 132-134). According to this hypothesis, the successful synchronization of linguistic and cultural development can be crucial in determining whether a learner progresses in both language arts and psychological aspects of the target culture. The teacher's role in this process is to assess both stages of development in the learners.

Pearson (1988) recommends that teachers focus on concepts like ethnocentrism, cultural relativism, prejudice, and stereotyping in the second language classroom. She also supports a heightened awareness of personality factors in both teachers and students in the ESL classroom, specifically as they relate to culture shock. The concept of culture shock as a potential source of positive interaction in the ESL classroom is developed by Irving (1984), who stresses the need for teachers to deal with cross-cultural topics, maintaining that they are more often the source of communication breakdowns than are linguistic difficulties. She also cautions teachers to be aware that what a teacher or learner "communicates may not be what the person intended, especially when communicating with someone from a different culture" (p. 141). She attributes many of the potential breakdowns in crosscultural communication to different concepts of time, place, people, and situation. In addition, she notes that affective influences such as intentions, values, assumptions, and attitudes may further complicate communication between members of different cultures.

Brown (1987) discusses numerous sociocultural factors relating to the concept of culture shock in the classroom, emphasizing the need for both learner and teacher of a second language to understand cultural differences. 
He reiterates a concern of Bennett (1979) in not applying the 'golden rule' concept of doing to others what we might like done to ourselves when he states that individuals "need to ... recognize openly that everyone in the world is not 'just like me', that people are not all the same beneath the skin. There are real differences between groups and cultures." (p. 26). He adds that teachers can help learners move through the stages of acculturation by playing a therapeutic role that does not rush the process or avoid the feelings that must be dealt with in each stage. He maintains that this will enable learners to increase their chances for success in both language acquisition and second culture learning.

\section{THE ROLE OF THE LANGUAGE LEARNER'S CULTURE}

Recent research in schema theory (Carrell \& Eisterhold, 1983) emphasizes the importance of background knowledge in the process of reading comprehension. This is knowledge that the authors state may be "culturalspecific" (p. 562), thus causing the reader to read and interpret text through culturally-filtered glasses. Earlier studies by Johnson $(1981,1982)$ indicate that the cultural background of a topic may also have an impact on the ability of readers to comprehend the text. Meanwhile, Kaplan (1970) and Indrasuta (1988) purport that cultural differences contribute to the organizational patterns of written texts. Research by Osterloh (1980) also indicates that learners analyze texts differently based on culturally-based attitudes, and the differences in background and beliefs may require each individual to work through a series of new social experiences when reading in a second language. Likewise, work by Wolfson (1989) focuses on cultural differences in rules of speaking, noting that spoken languages exhibit important pragmatic differences that non-native speakers need to master along with the grammatical rules of the language. 
Applying these same concepts of schema-based learning to culture, Byram (1989) explains that individuals develop their "social space" in a process of acculturation that is similar to the development of linguistic competence. The process is based upon interconnected webs or networks of meanings acquired through interactions among individuals, particularly the guidance of older individuals who teach "social skills and dispositions" (p. 110). In cases of culture, he argues that schemata represent generic concepts, including the underlying sequences of events that are part of all individuals' internalized cultures that have been taught since birth.

According to Irving (1984), a person's internalized culture also allows one to perceive things that are not perceived by others, or conversely, not to perceive things that are perceived by others. As a result, aspects of one's internalized culture such as notions of formality and deference to superiors may influence what one consciously and unconsciously communicates in the classroom. Likewise, she maintains that beliefs concerning teacher/learner roles may be so ingrained that even if students are intellectually aware of differences, they may find it difficult to act in accordance with their perceptions of what those roles should be, choosing instead to bow or use forms of address that portray the more formal atmosphere they are comfortable with.

Commenting on the differences in expectations based on cultural background, Christison and Krahnke (1986) explain that students and teachers may have very different ideas about what should be taught and learned in the ESL classroom. Oftentimes, they note, those differences may not be verbalized because " students may voice only what they think their teachers want to hear" (p. 64). At times, they remark, even this may be curtailed because students are 
reluctant to engage in verbal interaction inside or outside the classroom, viewing their own English as inadequate for the task required.

This seems to suggest that basic problems can arise in the ESL classroom when teachers and learners have such different ideas about the roles of communication and interaction in the learning of a second language. If students feel intimidated by their lack of expertise in the language or ambivalent about the matter of informality and role expectations in the ESL learning environment, they may be reticent to respond with the spontaneity and enthusiasm that their teachers expect and reward. While students may readily acknowledge the value of speaking and interaction in the learning of a second language, they may be uncomfortable and even unwilling to engage in the kinds of activities they recognize as valuable.

In general, these studies show that individual learners approach the process of second language acquisition differently depending on culturallybased assumptions and experiences, and that the acquisition of cultural and linguistic competence follow similar paths. Teachers need to take into account the differences that may exist in perceptions of teacher/learner roles and the cultural forces that influence communication in the classroom, just as they consider the preparation and styles of learning that various students bring to the ESL classroom. This may require teachers to be as attentive and active in determining reciprocal attitudes and assumptions about language learning as they are in fostering communicative activities to aid in language acquisition.

\section{JAPANESE AND AMERICAN CULTURAL VALUES}

The research on the influence of the language learner's individual culture as it applies to classroom success serves to complement the wealth of 
information that is available on the differences in cultural beliefs, attitudes, and values among peoples of the world. One particularly fertile area of comparative cultural study is that of the United States and Japan. Numerous American and Japanese researchers have looked into the apparent and not-so-apparent differences in culturally-based beliefs and values. Among the most frequently cited are Benedict (1934, 1967), Nakane (1970), Stewart (1971), Condon \& Saito (1974), Doi (1974), Barnlund (1975), and Reischauer (1977). These writers tend to identify and categorize the cultural values most prominent in American and Japanese societies while attempting to offer explanations for differences. They also cite numerous areas of potential conflict between cultures.

Among the areas mentioned that may cause cultural misunderstandings are those of educational goals and objectives. Becker (1990) notes that there are major differences between Japan and the U.S. in their respective university systems. The Japanese, he explains, view the modern university as somewhat of an elite intellectual goal. Unlike American students, those in Japan do not expect to acquire job-related skills, nor do they expect to learn basic math and English that they didn't adequately master in high school. In addition, he explains that the Japanese do not view the university as a place that mature adults return to, seeking intellectual stimulation and personal growth. This contrasts strongly with the goals of many universities in the United States that tailor programs to offer specific job-related skills, introductory and remedial courses, or post-graduate enrichment studies. According to Becker, these basic differences in educational philosophy have more to do with deep-seated values about family demands and expectations than they do with curriculum or teaching methods. 
Another area of deeply rooted beliefs that may present problems is that of language acquisition. According to Hall and Beardsley (1965) and Becker (1990), the study of the Japanese language reinforces important concepts of social stratification and national exclusiveness because there are so many levels of politeness demanded of a fluent speaker and because there is a need to stay in regular contact with the language and its speakers to be considered part of the group. In fact, as Enloe and Lewin (1987) explain, the Japanese believe their culture to be "uniquely homogeneous and advanced", and therefore one that "can be completely understood only by those who participate totally within it" (p. 245). The result is that language is considered to be a repository of national identity, and learning a second and competing language is somewhat threatening to that identity. This is especially obvious in the case of returnee children who have lived abroad for any period of time. Upon their return, they no longer receive the unqualified support that they are even Japanese any more. As Enloe and Lewin (1987) explain: "Both personally and culturally, their identity is at issue" (p. 246).

A final area of potential cross-cultural conflicts between Japan and the United States is the realm of international business relations. Perhaps owing to the recent growth of Japanese economic power, a large amount of information has been written concerning the cross-cultural aspects of Japanese/American business relations. Triandis, Brislin, and Hui (1988) focus on the cultural variations arising from patterns of individualism versus collectivism, a topic that is also mentioned with regularity when discussing American and Japanese classroom behaviors. They maintain that behaviors within collectivist societies such as Japan differ widely from those in individualist cultures such as the United States in all areas of personal interaction. Collectivists are "more 
associative with their ingroups, and more dissociative towards their outgroups than are individualists" (p. 277). These conclusions are likely to have strong implications for both business leaders and educators who must often serve as cultural referees in interpersonal negotiations.

In a related study, Sudweeks et al (1990) note that a lack of understanding of another's culture causes participants to remain at low-intimacy and trust levels in personal and business relationships. While this study does not discuss classroom behavior per se, it does emphasize topics that are of concern to both business and academia. These are topics having particular applications to business executives studying in another culture who bring with them the cultural values of a foreign workplace and educational setting that are often significantly different from those of their host country.

It seems, then, that many of the same beliefs and values underlie assumptions and behavior in both the academic and business worlds. When the participants in the interchange are Japanese and Americans, there can be both predictable and unpredictable outcomes.

\section{THE ROLE OF CULTURE IN PERCEPTIONS OF TEACHER/STUDENT ROLES}

Little empirical research has been conducted on the cultural differences in the roles of the teacher and the student in the ESL classroom. Most of the information in this area comes from individual recountings of cross-cultural difficulties by ESL and EFL classroom teachers, and much of it is often conveyed in the form of anecdotal observances from personal experiences at home or abroad.

One researcher who has attempted to establish a framework for the cross-cultural analysis of teaching methods is Furey (1986). She examines five 
areas in which cultural differences may affect teaching and learning in the classroom, a place that she views as a subculture unto itself, with tightly patterned ways of thinking and acting appropriate to that specific environment.

The first area that she looks at is that of cultural values. Her discussion defines differences in individualism and group orientation, attitudes toward the use of time, and basic values about the purpose and importance of education. She highlights differences among various language groups, including the divergent ways in which Japanese and American learners traditionally view competitiveness in the classroom. She notes that Japanese students tend to be highly competitive with their peers in attempting to gain admission to the best universities and ultimately membership in the desired group (company), while American students generally view individual success as the ultimate goal, with group identity and membership as something less important.

This attitude toward competition continues in the Japanese corporation, according to Ouchi (1981), who explains that the Japanese cultural concept of what is logical or good is quite different from the American position. As a result, he points out that what seems correct and obvious to one might appear comically flawed or illogical to another.

In her discussion of the second area, views toward the teacher, Furey focuses on differences in perception regarding the status or prestige of teachers, proper distances maintained between students and teachers, and ideas concerning the specific roles of teachers, i.e., their rights and obligations. She points out that teachers in some cultures are treated with a good deal more formality and distance than they are in the United States, and she associates this with their status as "guardians of a sacred body of knowledge" (p. 21). She also notes that Japanese students are among those who are less likely than 
their American counterparts to question or challenge a teacher. Likewise, she maintains that students who have been educated in societies where teachers are authority figures may require rather strong direction in the classroom instead of abundant choices and independence. These aspects of the teacher's role are also dealt with by numerous Japanese and American researchers, including Nakane (1970), Shimahara (1975), Hofstede (1983a), and Hendry (1987), all of whom substantiate Furey's observations that Japanese society generally views teachers with more respect and gives them more direct control over enforcing discipline and moral training than does American society.

Becker (1990) maintains that the formal vertical relationship between teachers and students is deeply imbedded in the Japanese culture. He explains that the kanii character for learning is "a picture of hands putting 'stuff' $(x ' s)$ into the head of a child; thus the notion that learning means receiving information is deeply rooted within the very language from which Japanese perceive their world" (p. 431). This seems quite contrary to a common idea in American education that learning is a process of discovery, one often directed by student interests and initiative. It also sets up possible areas of conflict if teachers expect students to take responsibility for directing aspects of their own learning such as determining the style and content of essays or the format for oral presentations.

The next category mentioned by Furey is modes of learning, in which she outlines differences in learning strategies among cultural groups. Of particular interest in this section is the allusion to educational systems like the Japanese that place a heavy emphasis on rote learning and memorization. She points out that students from this kind of educational background may have difficulty 
with teaching styles that employ problem-solving strategies or demand what American teachers might consider to be creative, critical thinking skills.

Nakane (1970) and Becker (1990) also note that the need for Japanese students to memorize thousands of individual characters tends to reinforce the idea that education is rote memorization of what is handed down by the teacher or printed in books. Again, this may be an area of potential miscommunication if ESL teachers expect students to predict possible scenarios or react with individual interpretations to new material.

The fourth area that Furey discusses is teacher/student interaction patterns, noting that many of the communicative activities that have become popular in recent years are not the kind that Japanese students are comfortable with. She says that much of the discomfort experienced in such activities may come from uncertainty about expectations of how group consensus is reached in ESL classrooms. Her comments reflect the views of Wagatsuma (1984), Hendry (1987), and Peak (1989), who explain that the process of reaching group consensus among the Japanese is a skill that is highly valued and therefore carefully taught in the classroom as an important component of the socialization process. It is also a duty assigned to classroom teachers. Japanese students learn to deal with conflict resolution within the group, an integral part of which is learning when and how to display public and private "faces". The result is that much of what is understood in Japanese negotiations and interactions is unspoken, being read through non-verbal communication. It falls into the realm of communication patterns identified as "high-context" by Hall (1976), where "most of the information is either in physical context or internalized in the person, while very little is in the coded, explicit transmitted part of the message" (p. 79). American communication patterns, in contrast, 
with their strong dependence on what is spoken, often fit into the category of "low context", one in which "the mass of the information is vested in the explicit code" (p. 79).

On a related issue, Maurice (1986) states that Japanese students of ESL sometimes interpret the American style of direct, argumentative debate as "insincere and the conversation as an artificial game" (p. 45). Confronted with such 'unusual' methods of reaching consensus and debating topics in the ESL classroom, Japanese students can be quite confused about their expected roles and therefore reluctant to take part in certain kinds of classroom activities, at least with the spontaneity desired by their instructors.

The final aspect of Furey's framework concerns norms of interaction between teachers and students. In this section, she examines a number of rules of social interaction, most of which she argues are unconscious and quite complex. These constitute what she earlier referred to as a classroom "subculture", in which the rules concerning body language, personal space, and speech acts vary from one culture to another. She maintains that these are important aspects of how students and teachers perceive one another and interact within the learning environment.

For Japanese students in an ESL classroom, these new expectations regarding interaction patterns may be somewhat disorienting as they seek to apply previously-learned concepts of turn-taking, individual acknowledgement, and voiced agreement and disagreement. For adult language learners with strongly established views about deference to teachers and senior group members, this new classroom subculture might be even more unsettling. As Barnlund (1975) explains, the rules of meaning that distinguish the Japanese from American culture must be identified, particularly because they are so 
intimately incorporated into styles of presentation. Failure to do so, he warns, can lead to problems of misperception and miscommunication on the part of individuals from both cultures.

In general, Furey's framework will provide a checklist in this investigation for areas of possible misunderstanding, miscommunication, or disagreement in the cross-cultural classroom setting and how students and teachers perceive their own and one another's roles.

While Furey's framework is useful in analyzing various aspects of perceived differences regarding teacher/learner roles in the ESL classroom, the work of Hofstede (1980) is valuable in providing empirical data to support a theory of universal categories of culture. He proposes a four-dimensional model of cultural differences based on suggestions by anthropologists that there be universal categories of culture. He argues that cross-cultural studies lack a theory of culture but that his research provides one.

In his argument Hofstede first defines culture as "the collective programming of the mind which distinguishes the members of one human group from another" (1980, p. 25). Then, he specifies the elements that compose culture, and he identifies four main dimensions along which dominant value systems of culture can be ordered: power distance, uncertainty avoidance, individualism/collectivism, and masculinity/femininity. The value of such a theory lies in the fact that it provides a framework for investigating all cultures and for comparing one culture to another.

Hofstede's Four-Dimensional (4-D) Model of Cultural Differences was developed after many years of research in which he administered a 32-item work-related value questionnaire to 116,00 workers (managers and nonmanagers) in 40 different countries. The workers were all employees for a 
multinational corporation. Eventually, the study was broadened to include workers in another ten countries and three multi-country regions.

The 32 items on his questionnaire initially involved three factors in intercultural communication: individualism/low power distance, masculinity, and uncertainty avoidance. Later, the first category was divided into two dimensions, individualism/collectivism and power distance, thus creating the four dimensions in the 4-D Model of Cultural Differences.

Hofstede also applied his construct to cultural differences in education (1986). In the introduction to his research on this aspect of cross-cultural communication, he noted,

As teacher/student interaction is such an archetypal human phenomenon, and so deeply rooted in the culture of a society, cross-cultural learning situations are fundamentally problematic for both parties (p. 303).

According to Hofstede, the archetypal pairing of students and teachers from different cultures is one that has continued from early recorded history up through the present. He links the archetypal roles to the values that he claims are basic to each culture. By values, he means "broad tendencies to prefer certain states of affairs over others" (1980, p. 19). These values, he continues, are what cause individuals to make judgments about whether something is good or evil, right or wrong, or rational or irrational, allowing for the possibility of frequent conflicts in cross-cultural situations such as the classroom.

The first of Hofstede's four dimensions, power distance, explains how individuals within a culture tolerate inequality among persons of more and less power. This includes how workers deal with a superior's style of decisionmaking across professions. With relation to education, it involves questions regarding respect of students and teachers for one another inside and outside 
the classroom, decision-making and leadership roles for both students and teachers, expectations of student assertiveness in the classroom, and methods of conflict resolution relating to the school environment.

The second dimension, uncertainty avoidance, relates to concepts such as the comfort level provided by the amount of structure in learning situations, expectations about teachers providing answers to all questions, and attitudes towards intellectual disagreement in the classroom.

The area of individualism/collectivism treats topics related to the value placed on innovation in education, reinforcement provided for individual opinions within group settings, methods of maintaining harmony within groups, attitudes toward saving face within the classroom, and individual achievement and academic degrees.

The final category in the four-dimensional model, masculinity/femininity, deals with values associated with reward systems used in the classroom, choice of academic careers, competition and cooperation in learning, and attitudes toward friendliness and intelligence in the teaching staff.

The four dimensions of Hofstede's Model of Cultural Differences along with aspects of Furey's framework for cross-cultural analyses of educational themes will provide the basis for survey items and interview topics in this study. The primary research tool employed in this study will be the Cross-Cultural Education Survey developed by Nelson (1991) to investigate cultural difference in teacher/student roles, classroom interaction patterns, and learning strategies (see Appendix A). The survey is derived from predictions made by Hofstede regarding differences in teacher/student and student/student interaction patterns(1986). Those predictions were not empirically tested, however, and 
one of the purposes of the study by Nelson and Brown is to conduct such an empirical study of Hofstede's suggested outcomes.

While Nelson's survey was designed to investigate these topics quantitatively, its use in this study will be to serve as points of focus in openended interviews. Those interviews with Japanese businessmen studying ESL in the United States will provide the data for this qualitative study on perceptions of student and teacher roles in the second language classroom, looking at individual views, attitudes, and experiences. 
CHAPTER III

METHODOLOGY

\section{SUBJECTS}

Information for this study was collected from five Japanese businessmen studying English as a Second Language (ESL) at a small private college in the Pacific Northwest. Two of the participants attended a six-week session of classes, while the other three took part in a five-week program. In both cases, the course of studies emphasized communication skills considered essential for international executives using English as a non-native language in both business and social situations. All of the informants in this study were also members of this researcher's Current Events/Listening Skills Class, a course emphasizing speaking and listening activities for upper-intermediate and advanced learners of ESL.

The individuals in this study had all been selected by their respective companies to study in the United States as recognition of their outstanding employment histories and as training for possible assignments requiring communicative skills in English. In age and in number of years of formal English study, there was a certain homogeneity among these businessmen. Their ages ranged from 29 to 35 , with all having completed eight years of English study in Japanese schools and most having followed up on their university or technical degrees with additional English language study. In the areas of professional training and in current job classifications and 
responsibilities, there was more variety among this group of businessmen, as the following descriptions indicate.

The first two participants worked for the same multinational steel corporation. Osama, (a pseudonym, as are all the names assigned to the businessmen in this study), a 35-year old sales representative in the metals and mineral division, had a degree in Economics from a large Japanese university. His co-worker, Toro, a 34-year old salesman of industrial gases, held a Social Sciences degree from a prestigious Japanese university.

Osama had been studying English to enhance his career opportunities in the export division of his company. To that end, he had taken classes for the preceding two years at a Berlitz school in Japan, and he regularly listened to a taped self-study program in English on the Japanese public radio station while commuting by train each day. For him, the technical language of his business dealings was not a problem, because, as he explained it, the questions involved topics he could anticipate and prepare for beforehand. He regularly used English while dealing with clients in Singapore, Thailand, Malaysia, and Australia. Spontaneous conversation, however, presented problems for Osama. As he remarked, "When I have lunch or dinner, it's very hard time for me."

For Toro, English study was not only a way to proceed up the corporate ladder, it was also a way for him to broaden his horizons by offering him the opportunity to travel and learn about other cultures. In his words, "I think we Japanese do have to learn English conversation. We want to communicate other nation's people, and we want to touch other people's culture." (Note: this quotation and all others are copied exactly as spoken.) Consequently, he 
maintained regular contact with an American-exchange student he had met while studying at the university, a student who had taught him English "more clearly or brightly" by providing examples of "real English conversation", not the kind studied in the Japanese classrooms of his experience. Toro seemed quite comfortable with his communicative skills in English, and his ability to negotiate important business contracts while using English seemed to verify that confidence. He had recently completed the purchase of a gas production plant in the United States for his company, handling all the negotiations in English.

The third informant in this project, Aki, was a 29-year old pharmaceutical engineer who worked for a multinational corporation specializing in chemical production. He had completed a master's degree and two years of a doctoral program in Chemical Engineering before joining his company. His experiences studying and using English were limited to his formal education in the Japanese school system. He seemed less comfortable and confident than the other interviewees in understanding and using spoken English, choosing to answer many questions very directly with little elucidation.

The two remaining participants worked in the same section of a large multinational steel corporation. Shido, a 31-year old plant manager, had earned a master's degree in Mechanical Engineering. He had studied English conversation for a quarter at another American university immediately prior to beginning this program. That experience had introduced him to what he termed "real conversation", more than the simple repetition and substitution drills that he remembered from his secondary and university English classes. According to Shido, he had never been asked to participate in a discussion class before 
studying in this country, and he found the new experience "very interesting, but sometimes difficult."

Hiro, the other interviewee, was a 30-year old civil engineer who had attended a technical school upon completion of his secondary education. Family constraints owing to his father's health and financial position had caused him to choose the technical school over a university for his post-secondary education. Like Shido, he had just completed a quarter of English study in the ESL program of a large American university immediately before beginning this program. As he explained it, he had been chosen to study English because he had consistently received "great recommendations" from his supervisors at work. He indicated that success in his English studies in the U.S. would allow him to move up to the next level in his corporation. Shortly after finishing this program, Hiro returned to his company, where he jumped two levels in the corporate ranks due to his improved scores on the company's English language exams. In addition to his English classes in secondary school and the technical college, Hiro had also studied English for about five years with other volunteers in weekly company-sponsored courses conducted by native English speakers. For him, it was very important to get away from classroom exercises and be able to practice what he called "the vivid English foreign people speak."

As a group, these five businessmen did in fact make up a rather cohesive and representative group of informants. In terms of age, background, and goals, there was much similarity, both to one another and to other groups of individuals being sent to the United States by Japanese corporations for the purpose of studying English. Likewise, the responses evoked by the the survey questions about perceptions of educational roles were indicative of many of the comments heard before by this researcher when discussing teacher/student 
interactions with Japanese executives enrolled in ESL programs. This is not to say that individual differences did not exist or surface during the course of the discussions or that new ideas did not find their way into the conversations, but rather, that the remarks of these five individuals often reaffirmed what had been observed by this writer and described by others while working with similar groups of language learner. In short, this did not seem to be an atypical group of Japanese businessmen working to improve their English language skills in a structured university ESL program.

\section{PROCEDURE}

The interviews for this study were conducted in English between individual informants and this researcher, except when the first pair of interviewees met together for their last two sessions because of time constraints. The interview sessions, usually lasting 45 minutes, were audiotaped, with informant(s) and interviewer sitting across a table from one another in a small conference room. Prior to the actual interview sessions, all participants received information about the goals and methods of this study. The interviewer also read over the informed consent form (Appendix B) with each individual, answered questions about it, and asked volunteers to take the form home to study before signing it.

The content of the interviews focused upon the responses by the informants to questions on the Cross-Cultural Education Survey developed by Gayle Nelson (see Appendix A). This questionnaire consists of 22 items seeking information about educational practices and beliefs in the respondent's home country and eight questions dealing with personal feelings about classroom interactions and various aspects of the workplace. This 
questionnaire is part of a quantitative study currently underway to investigate educational differences in various countries. It looks at cultural differences in the roles of students and teachers, classroom interaction patterns, and learning strategies, employing a Likert-scale ranking based on elements of Hofstede's Four Dimensional Model of Cultural Differences and its application to cultural differences in teaching and learning $(1980,1986)$.

Using the questionnaire developed by Nelson for that project, this study was designed to examine qualitatively the attitudes of Japanese businessmen studying ESL toward teacher/student roles and interaction patterns in the second language classroom. The survey questions, which the participants answered at home before the interview sessions, served as the bases for the open-ended discussions about each topic. Informants were encouraged to respond as honestly as possible to the questions, basing their answers on their own experiences and using as many examples and anecdotes as necessary to explain their responses.

The willingness of the businessmen to answer the questions and furnish details and explanations caused most sessions to go beyond the scheduled times that had been set aside for them. All of the participants seemed more than willing to continue talking, partly it seemed as an opportunity to practice their conversational skills, and partly it appeared as a chance to exchange ideas about personally engaging topics introduced by the survey items. There was a definite reluctance on the part of both interviewer and interviewees to end each session, an attitude reflecting the enthusiasm and interest present throughout this study.

Questions about the validity of this research were addressed with regard to both the measuring instrument (survey questionnaire) and the data-gathering 
techniques. With regard to the former, attention was focused on Hofstede's tables of possible differences in student/teacher and student/student interaction (1986, pp. 312-315). These are the sources for the questions on Nelson's survey form, and they are related to the four dimensions of Hofstede's model for cultural differences: individualism/collectivism, power distance, uncertainty avoidance, and masculinity/femininity. Hofstede constructed the model from data he collected in his study of work-related values across 50 countries and three multi-country regions (1980). The data were collected in subsidiaries of a multinational corporation with offices in each of those 53 areas.

While some might argue that employees from a multinational corporation are not representative of a culture, Hofstede posits that the use of personnel from such an institution is in fact valid research, because it allows for the control of other variables that might otherwise confound the results. By controlling variables like occupation, class, and age, he limited the study to an examination of culture. As Hofstede explains, he focused on the relationship between nationalities and mean value scores in developing his four-dimensional model, so that the countries, not the individual respondents, became the units of analysis (1986, p. 306). The scores for the particular countries and regions are included in Appendix $\mathrm{C}$, while the specific method of calculation for each score is explained in Hofstede's research (1983a).

The initial data used in developing the four-dimensional model of cultural differences came from respondents in 40 countries; however, Hofstede later expanded the study to include responses from employees in another ten countries and three regions. The additional data from those respondents further supported the parameters of Hofstede's original framework, and he notes that 
"their scores fitted well into the existing dimensions" he had previously established for his model (1986, p. 307).

Hofstede also compared the results of his research with anthropological studies of national characteristics by Inkeles and Levinson (1969). He found that the attributes of individual cultures which surfaced in his research closely correlated with the earlier predictions of Inkeles and Levinson. Eventually, Hofstede broadened his research to validation studies of the four dimensions outside the subsidiaries of the multinational corporation, correlating his results with conceptually-related data in about 40 other studies (1983a). With each of these developments, Hofstede has been able to validate the constructs of his original model of cultural differences, first by expanding the breadth of the original study to an additional thirteen countries/regions and finding that the model maintained its integrity, then by comparing his findings with the predictions of noted anthropologists and finding that his categories correlated closely with theirs, and finally by matching the results of his research with that of some 40 other related studies and finding that those studies further validated his original concepts of culturally-based differences.

The dimensions of Hofstede's model have also been used by other researchers to organize and explain a number of related interpersonal phenomena. Forgas and Bond (1985) used it in explaining perceptions of interaction episodes; Gudykunst and Nishida (1986) employed it to help describe concepts of communication associated with relationship terms; and Gudykunst and Ting-Toomey (1988) found it useful in organizing differences in affective communication. In the process, these researchers and others have accepted and made use of Hofstede's four-dimensional model as a valid 
construct for examining cross-cultural differences in a variety of studies on interpersonal communication. It should come as no surprise, then, that Hofstede chose his own model to investigate patterns of student/teacher and student/student interactions, another area of interpersonal communication.

In applying his model of cultural differences to classroom interactions, Hofstede developed tables of possible differences that are organized along the framework of the four dimensions of his model. As noted earlier, these are the suggested points of difference from which Nelson selected items with which to construct the survey form used in this study.

The first area for which Hofstede listed likely points of difference in perceptions of educational roles was individualism versus collectivism, using those terms in an anthropological not a political sense. In this categorization, Japan is classified as a collectivist culture, where members belong to one or more tightly-knit in-groups. In such a society, primary responsibility is to the various groups, from which members cannot easily detach themselves. This designation of Japan as a collectivist society is well documented in literature with descriptions of the uchi (inside) and sote (outside) worlds of Japanese perception. Among the writers who have discussed this are Barnlund, 1975; Doi, 1974; Hendry, 1987; Ishida, 1984; and Peak, 1989. The United States, in contrast, is classified as an individualistic culture, wherein the members assume primary interest and responsibility for themselves and their families.

Scores from Hofstede's survey of individuals from these two cultures indicate that Japanese respondents ranked slightly below the midpoint, in the collectivist range with a score of 46 , (collectivist $=0-49$, individualist $=51-100$ ), while respondents from the United States ranked higher than those of any other 
country in the individualist range with a score of 91 . Items from Hofstede's tables that address these differences include questions about the values of group harmony, individual performance in the classroom, and innovation in teaching.

The second of Hofstede's areas of cultural differences was power distance, referring to the "extent to which the less powerful persons in a society accept inequality in power and consider it as normal" (1986, p. 307). In this category, Japanese respondents scored 54 and their U.S. counterparts 40 , indicating a lesser tolerance for perceived inequality in the United States, (high power distance $=100$ ). In comparing power distance scores with results of other cross-cultural studies, Hofstede (1980) found that students in high power distance cultures value conformity and display authoritarian attitudes more than those in low power distance cultures. In education, the power distance characteristic is also related to questions concerning teacher-centered versus student-centered activities, with those in high power distance cultures typically preferring the former. A number of writers, (Buck, Newton, \& Muramatsu, 1984; Feiler, 1991; Reischauer, 1977; and Shimahara, 1991), indicate that Japanese schools traditionally expect teachers to orchestrate all classroom activities from a clearly-defined curriculum.

The third area of interaction differences in education to which Hofstede applied the findings of his studies had to do with uncertainty avoidance. This characteristic, as he explains it, is the extent to which members of a culture feel uneasy in situations that they perceive to be "unstructured, unclear, or unpredictable" (1986, p. 308). In cultures that score in the high range in this area, there is a tendency to deal with uncertain conditions by maintaining strict codes of behavior and by relying on absolute truths. In cultures with lower 
uncertainty avoidance scores, there is a greater appreciation for relaxed norms of behavior, tolerance for differences, and acceptance of personal risks.

The data from Hofstede's work-related research ascribed a score of 92 to Japan and one of 46 to the United States, indicating that Japanese respondents are more apt to feel a strong need for well-defined codes of behavior and lists of rules. Related research supporting this position comes from Condon \& Saito, 1974; Gorer, 1962; Wagatsuma, 1984; and Rohlen, 1989, who indicate that Japanese culture tends to observe strict norms of behavior with an appreciation for both internal and external discipline.

The final characteristic for which Hofstede developed lists of suggested interaction differences in educational roles related to the concepts of masculinity and femininity. This category relates to specific values associated with gender differences that cultures use in sanctioning and promoting what are regarded as typical "male" and "female" behavior. When applied to the educational arena, this characteristic is evident in areas such as recognition of success and the use of reward systems in the classroom. It also pertains to students' preferences for either friendliness or intelligence in teachers.

Data from Hofstede's surveys ranked Japan as the most masculine culture of those studied, with a score of 95 , indicating among other things a preference for material success, assertiveness, and "whatever is big, strong, or fast" (1986, p. 308). Hofstede indicates that Japan's high score in the masculinity category "suggests a very strong performance orientation of Japanese men, in comparison to men from other countries" (1983b, p. 163). This he supports with results drawn by writers such as Benedict, 1946; Dore, 1973; and Whitehall \& Takezawa, 1968; identifying Japanese culture as one 
with a decided preference for achievement and success in both education and the workplace, that is for masculine values.

While Japan was the highest ranking country in the masculinity range with a score of 95 , the United States scored 62, representing a masculine leaning also, but to a lesser degree than in Japan.

In general, Hofstede's itemization of differences in perceptions of student and teacher roles gleaned from the data used to develop his four dimensional models reflects the findings of numerous other researchers in a variety of fields of interpersonal communication, including many dealing specifically with Japanese culture and its relationship to education. His suggested listings also provide a useful list of cross-cultural concepts with which to investigate differences in second language settings.

Further evidence for the validity of applying Hofstede's framework and topics to issues of classroom interaction is provided in Nelson and Brown's quantitative study of teacher/student roles in the ESL classroom (forthcoming).

Local questions about the validity of this measuring instrument were addressed by insuring that each participant fully understood all of the items on the survey. This was done by giving the form to the participants to study and complete at home, thus allowing them to devote as much time and effort as they might need to deciphering the content of the survey items and formulating their responses to them. When question arose as to the meaning of words or phrases, the interviewer first asked the respondents for their understanding of the troublesome language and then clarified meanings if necessary. Although the questions were written in English and not translated into Japanese, there were few instances in which the interviewees expressed confusion about meaning. At those times when the respondents had difficulty expressing their 
ideas in English, they were encouraged to use examples and anecdotes to explain what they were trying to communicate. At other times, they were encouraged to use the Japanese equivalents for words or phrases that seemed to have no translation into English. The one element of the survey that did provide initial confusion for the businessmen was whether to respond to the questions as they had felt while students in the Japanese school system or as they currently felt in their positions as adult workers studying abroad. The interviewer instructed them to talk about both positions, if and when they were different.

The open-ended discussions that developed around the survey questions served to verify and further clarify some of the data gathered in the Nelson and Brown study. As a result, by not invalidating the findings of that study, it further served to validate the use of the measuring instrument employed in both research projects.

The survey questions also demonstrated face validity in that they appeared to measure what they were intended to. The Japanese executives volunteered information from their experiences directly related to their stated perceptions of student and teacher roles in the second language classroom, results which this surveyed was designed to evoke.

With regard to the validity of the data-gathering techniques, the instructions given for the completion of the survey, the location and format of the interviews, and the recording and transcribing of data were identical for each of the interview sessions, conducted by one and the same researcher. These criteria were applied so as to minimize possible influences exterior to those present due to the individual informants' personal experiences, that is, to what are termed "situational factors" (Sellitz, Wrightsman, \& Cook, 1976, p. 166). 
Included were the attention given to interview style employed by the interviewer and the guarantee of anonymity by the study. Concerns about possible differences due to transient personal factors such as mood, state of fatigue, and mental set were addressed prior to each session by enquiring as to the informant's interest, energy level, and time constraints. Without exception, all informants voiced a strong desire to participate in each of the sessions and to discuss the items on the survey, indicating, it seemed, a definite openness and willingness to cooperate and be forthright in their responses.

Because this study concerns the perceptions of the individual informants, questions might be raised as to whether the individuals' true positions are being measured. In the absence of direct knowledge in this area, Sellitz, Wrightsman and Cook explain that "the validity of an instrument is judged by the extent to which its results are compatible with other relevant evidence" (1976, p. 170). They further note that the nature and purpose of the measuring instrument is what constitutes relevant evidence.

In this study, the survey is not being used as a predictor of a certain type of behavior but as a basis for inferring the degree to which individuals possess certain feelings presumed to be reflected in their answers to the survey questions. Those perceptions cannot be pointed to or identified with a single specific kind of behavior; rather, they are abstractions or constructs. The process of validating this kind of measuring instrument is referred to as "construct validation" by Chronbach and Meehl (1985), who maintain that the definitions of such constructs consist in part of sets of propositions about their relationships to other variables; that is, other constructs or directly observable behavior. Thus the question seems to be whether the findings from this measurement tool (the survey) are substantiated by data from other sources. As 
indicated earlier, it is impossible to prove the validity of individual perceptions, but as has been shown, it is possible to substantiate them with the findings of other researchers writing about interpersonal communication issues in Japanese culture. Suffice to say, that in this study special care was taken to ensure the consistent and conscientious relay of information in settings that promoted openness and confidence.

Questions about the reliability of this method of investigation, "the extent to which the results can be considered consistent or stable" (Brown, 1988), might be addressed rather succinctly. Since this study examined the responses of a very limited number of respondents, it is not clear what the results would be if it were given to another similar group. Because it is based upon a structured questionnaire, there is no reason to assume that it would be unreliable. It would have to be administered to a much larger group to develop satisfactory reliability norms. There is satisfaction, however, in knowing that when this researcher used the same survey in two earlier instances, one with an Indonesian student studying ESL and the other with two Japanese businessmen involved in a program similar to that of the participants for this study, the answers received from the pair of Japanese businessmen were often quite dissimilar to those of the Indonesian student but regularly very similar to those of their countrymen in this particular study. While it would be unwise to generalize about the reliability of this form from these few examples, the results do not indicate that the form and process are unreliable.

Owing to the length of time that the participants were studying in this program, it was impossible to administer this survey more than once to each individual. The length of time required to conduct the interview sessions (fourto-five weeks with each participant) did not allow for more than a single 
administration of the survey to each participant. In addition, it seemed unlikely that individual perceptions would change markedly within the time frame of their language study program. While a test/retest check for reliability was not possible with this study, such a measure was used by Nelson in the quantitative study of perceptions about student/teacher roles using the same survey form. The test/retest reliability results from that study were .91 , indicating a high degree of instrument reliability for the survey form in that project. This is not meant to say that the measuring instrument was used in the same way for both studies, since its use in one was quantitative and in the other qualitative. Nevertheless, because this study worked closely and in depth with individuals' reactions to the particular survey items, it appears that this provides strong support for the consistency and stability of the survey form.

Consideration was also given to establishing another measure with which to assess the participant's positions on the items being surveyed, specifically videotaped interactions of the participants in actual classroom situations. This idea was rejected because the researcher was unable to gain access to classroom situations other than his own with the participants, and videotaping and discussing classroom procedures of a class with just interviewer and interviewees seemed rather contrived. In addition, this researcher was somewhat concerned that videotaping his own class to examine student perceptions of classroom interactions might produce rather skewed results, since this was the area that the two parties had been discussing in depth at regular sessions. Finally, that possibility also seemed to jeopardize the integrity of the regular class meetings between the researcher and participants, interactions which this instructor had guaranteed would not be affected by their participation in this project. 
Upon completion of the interview sessions, this researcher transcribed the audiotaped conversations, developing a set of field notes with which to work. Study of those field notes revealed several thematic threads that surfaced regularly from the interweave of questions and answers. Those themes were: student perceptions about individual versus group behavior and responsibilities in the classroom, the status of creativity and order in language learning, and the role of examinations in the Japanese educational system.

Each of those themes serves as a major point of focus in the ensuing discussion. 


\section{CHAPTER IV}

\section{DISCUSSION}

Each society has developed specific ways of defining the nature of its universe, including the processes by which individuals establish, develop, and maintain interpersonal relationships. Communication identifies the nature of those relationships, sometimes with words, sometimes without. The communication patterns that one is familiar with are also shaped by one's background of cultural beliefs and values, which provide a frame of reference for examining and categorizing reality. A result is that people create different worlds for themselves that are distinctive and often unlike the worlds that other individuals occupy, particularly those of different cultures.

In essence, the frame of reference that exists inside each person's head is the only world that each person really knows. It is a view that is influenced heavily by the individuals, institutions, and information around that person. It is shaped by one's own society and its views of the universe, a perspective with a coherent set of rules and behavior based on its own premises. Few individuals, however, recognize the cultural assumptions upon which their societies' cultural norms rest. As an example, Stewart and Bennett (1991) note that middle-class Americans usually think of themselves as active, competitive individuals in a world of other success-oriented individuals who view impersonal cooperation as desirable (p. 13). This, the authors maintain, is a view of reality that is culturally-relative and one that is not necessarily shared by members of other cultural groups, even groups within the United States. In contrast, Wagatsuma 
(1984) explains that Japanese generally perceive social relations to be based upon interdependence among members of the group, where dependence and compliance are not only condoned but at times encouraged (pp. 372-73).

For each society, then, there are accepted norms of behavior and attitudes about social interactions that members assume are necessary for the development and maintenance of healthy interpersonal relationships. When individuals from one culture cross the boundaries into the domain of another culture, they may encounter unfamiliar and conflicting assumptions about the form and function of communication patterns considered essential for successful interpersonal relationships. The English as a Second Language (ESL) classroom is one location where this interweaving of cultures and cultural assumptions is a regular occurrence. When this setting involves students from Japan and instructors from the United States, the opportunity exists for widely divergent assumptions about the perceptions of their respective roles.

To better understand the nature of interpersonal relationships in such a cross-cultural setting, it is helpful to examine the participants' interpretations, conceptions, and explanations of their interactions. One method of studying the various aspects of those relationships is to isolate themes in the participants' accounts of their experiences and perceptions. Spradley (1979) defines a theme as "any cognitive principle, tacit or explicit, recurrent in a number of domains and serving as a relationship among subsystems of cultural meaning" (p. 186). He maintains that these themes, most of which are tacit and taken for granted, connect different domains of meaning while remaining interrelated and overlapping. An analysis of themes, then, forces the researcher to look at more than just the parts that make up systems, the personal relationships. It also compels the researcher to look for systems of meaning that can be integrated 
into larger patterns. The focus of this study, then, is to analyze themes that emerged from discussions with Japanese businessmen about perceptions of student/teacher roles in the ESL classroom.

During the course of this study, three themes surfaced repeatedly, connecting many of the domains within the second language subculture. They were: student perceptions of individual versus group behavior and responsibilities in the classroom, the relationship of order to creativity in language learning, and the role of examinations in curriculum design and content. These concerns served as foci for many of the discussions generated by the interview sessions, and they appear to be important issues relating to the perceptions of student/teacher roles by the five executives in this study.

\section{INDIVIDUAL VERSUS GROUP BEHAVIOR AND RESPONSIBILITIES}

For any ESL teacher who has worked with Japanese students, the term, "We Japanese", is likely to be very familiar. It is a phrase that is used by many Japanese-speaking students in describing what seems to be a national consensus of ideas, opinions, and characteristics. For teachers from cultures of a less collectivist nature, say the United States, it may sound somewhat unsettling to hear individuals purporting to speak for what seems to be an entire society. In fact, if teachers from the United States couched their descriptions of American society in a blanket phrase like, "We Americans", they might be accused of using language that is racist or politically incorrect, especially given the current emphasis on recognizing the cultural diversity within these national boundaries. For the group of informants in this study, "We Japanese" was a phrase commonly employed to introduce comments about group-related norms 
and beliefs they identified with their culture. It was also one which they seemed to be very comfortable using.

The strong sense of group membership in Japanese society has been cited as a characteristic that differentiates Japanese culture from other collectivist societies, those that are shaped by networks of extended families, tribal groupings, or caste systems (Triandis, Brislin \& Hui, 1988). It is also a key element in defining who is and who is not Japanese. According to Wagatsuma (1984), membership in the group is an essential Japanese cultural assumption. He notes that, "In the Japanese assumption no group can exist without its individual members, and no individual can exist without being a member of the group" (p. 374). In this sort of relationship, individuals and the group work toward the same goals in a harmonious manner to the point that, "The group's goals become the members' goals" (p. 374).

The importance of group membership and group identity was regularly apparent and consistently in the fore during the interview sessions in this study. The importance was apparent in the descriptions by each businessman of his educational background and prior experiences in learning a second language. It often came to the fore while discussing the forces at work in developing and fostering group consensus and harmony in the classroom and in the workplace. It was one of the most obvious recurring themes to emerge throughout this research, linked primarily to the differences relating to collectivism/individualism and masculinity/femininity in Hofstede's Four-Dimensional Model of Cultural Differences.

The fabric of these discussions developed from the following items on Nelson's Cross-Cultural Education Survey (Appendix A). The following table indicates participant responses to the items on the survey form: 


\section{PARTICIPANT RESPONSES ON SURVEY ITEMS - PART A}

Question number

19. Students choose courses because vs. they are interested in them.

$$
A=9 \quad B=10 \quad C=10
$$

Students choose courses for career (job) reasons.

15. Students should blend in with other students, to be part of

vs. Students want to be noticed, to be the group.

$$
A=2 \quad B=3 \quad C=1 \quad D=3 \quad E=6
$$

5. Learning is for the young.

$$
A=2 \quad B=1
$$

vs. One is never too old to learn.

$\mathrm{C}=2$

$\mathrm{D}=2$

$E=2$

13. It is okay to disagree with the teacher.

$$
A=9 \quad B=8
$$

vs. It is not okay to disagree with the teacher

$$
\mathrm{C}=1 \quad \mathrm{D}=5 \quad \mathrm{E}=8 \text { (harmony should be maintained. }
$$

vs. Emphasis is on "new".

1. Emphasis is on tradition, the way things have always been done.

$$
A=1 \quad B=2 \quad C=4 \quad D=1 \quad E=3
$$

4. Teachers avoid openly praising (saying positivethings about) students.

$$
A=5 \quad B=2
$$

vs. Teachers openly praise (say positive (say positive things about) students.

9. Students speak in class when called on by the teacher.

$$
A=2 \quad B=1
$$

$\mathrm{C}=2$

$D=1 \quad E=5$

vs. Students volunteer answers when the teacher asks a question.

$C=1 \quad D=3 \quad E=1$

17. Students may speak in class when they want to.

$$
A=10 \quad B=9
$$

vs. Students speak in class only when asked by the teacher.

$\mathrm{C}=10$

$D=9 \quad E=9$
$A=$ Toro
$\mathrm{B}=$ Osama
$\mathrm{C}=\mathrm{Aki}$
$\mathrm{D}=$ Shido
$E=H i r o$

From their earliest experiences in the Japanese educational system, the participants recalled that they had learned to put the concerns and goals of the group before those of their own. In many areas related to education, there was no question as to which were most important, group goals or individual ones. The development and maintenance of group goals, including those initiated in the classroom, were of primary importance. From the very beginning, in their 
decisions about what to study, the businessmen indicated that they really had no choices. They were already being grouped into a single unit following a standardized curriculum toward a common goal: admission to prestigious universities or respected technical schools that would guarantee occupational security and group membership for life.

The course of studies for each executive in this study was remarkably similar to those of the other participants in both goals and content. A part of the mandated content was the study of English for six years in junior and senior high school. As one of the businessmen, Toro, noted, "Everybody learns English from junior high school," adding this qualification, "However, most Japanese can't speak English so well." Instead, he explained, the result is that, "We Japanese are very good at tests of English."

As a required part of the Japanese curriculum, English study for these five individuals was very similar. According to each of the executives, the Japanese school system taught them reading, vocabulary, and grammar skills, all with the goal of passing the rigorous exams for secondary and postsecondary school admission. Because the exams are in written form and because most of the English teachers are not native speakers, little if any emphasis is given to oral and aural language skills. What is important, they indicated, is being able to answer multiple choice questions about the language. Summarizing the process, Osama remarked, "In Japan it's very important to study English to join the university. Everybody must do it." And, as he and the other informants explained, everyone does it in essentially the same way, through a curriculum carefully structured and closely adhered to.

In Hofstede's (1986) tables of differences in teacher/student interactions, the choice of academic subjects based on their relationship to future career 
opportunities is linked to the concept of masculinity within a culture, an area in which Japanese culture scored higher than any other (see table in Appendix). In "masculine" societies, emphasis is placed on material success and performance orientation. These are traits that Hofstede also identified in other "masculine" cultures such as Germany and the United States (1983, p. 163). In this study, the choice of courses also seemed to be linked closely to the concept of group identity and membership, insuring that all students be prepared for roles in school and eventually in the workplace.

Osama expanded upon the importance of group identity and goals by noting that in Japanese classrooms value is placed not so much on individual achievement as on the ability of an individual to function within the group. He developed this idea by explaining that in the classroom, "We learn cooperation, cooperation to win in soccer game(s) or baseball or any game." He continued by stating that the individual is not emphasized in classroom activities, claiming that when one tries to be an individual, "That person is very missing from another people." He added that when a person places value upon himself as an individual, "He is alone, and without other people in his group. Then he cannot go. It will be difficult for him to go his way."

Developing this idea begun by Osama in one of their paired interviews, Toro explained that putting the individual before the group causes a student to "become outside, isolation." To prevent oneself from becoming an "isolation person", as he termed it, Japanese students "have to cooperate together," because, "we don't hope for isolation."

These comments referred to the question of whether students wished to blend in with other students and be part of a group or whether they preferred to be noticed and visible. When responding to this item on the survey, the 
businessmen were unanimous in their declaration that Japanese students preferred to blend in with the group. To be visible seemed to be more than just the opposite of blending in, however. It seemed to be closely identified with the perceptions of isolation and loneliness.

Besides being a major concern of these informants, isolation from the group is also a key concept often cited in the documentation of difficulties experienced by Japanese returning to their homeland after extended periods abroad. Enloe and Lewin (1987) note that the fear of isolation and loss of group support is so strong among some Japanese that many businessmen choose not to take their families with them on long-term assignments overseas. They feel that both their personal and their cultural identities may be lost or polluted. This was verified by one of the participants, Hiro, who indicated that he would not bring his family to the United States while he was studying and working here. He felt it would be, "Too difficult for them when they must return to Japan." Interestingly, no member of this group of businessmen mentioned that he feared becoming "isolated" while out of the country. Regular contact with co-workers from their corporations may have been the assurance that each needed to maintain a sense of group cohesiveness while living abroad.

When asked to describe classroom processes that encourage or nurture group cohesiveness and identity, both Toro and Osama were initially at a loss for words. Eventually, Toro suggested that the process is "very natural", explaining that "we learn naturally, not by teaching." When asked to give examples, both businessmen related how the idea of "teamwork" is regularly emphasized in Japanese schools, apparently contradicting Toro's claim that this is a natural process that is not explicitly taught. 
Osama further explained and contradicted the "natural" aspect of learning teamwork with his remarks explaining that teamwork is in fact explicitly taught and reinforced by the Japanese educational system: "When they ask students what is most important for winning, they answer 'teamwork'. It's teamwork, not individual power. And the schools always teach teamwork." His comments referred to the results of a survey that he recalled about student perceptions of values that are needed for academic and corporate success in Japan.

The concept of teamwork was one that they continued to discuss, with Toro furnishing examples of how teachers use stories to reinforce that value. One story he related had to do with three strong men trying to defend a bridge. When they were challenged to fight individually, he explained, none was strong enough to fight off the enemy alone. When they joined forces and fought as a group, however, they were successful in defending the bridge. To illustrate this idea, he demonstrated how easy it was to break a single pencil with his bare hands; but, when he put three pencils together, he showed that it was very difficult to break the closely-bound group. Asked whether the use of stories to teach such values was common, Toro quickly replied, "There is so much old story in Japan. Everybody knows, and everybody taught about that story from senior person." Later, he indicated that teachers are among those "senior" people entrusted with transmitting important value-laden stories that reinforce the primacy of group interests.

The transmission of important values from one generation to another also relates to Furey's (1986) discussion of the status assigned to teachers in different cultures. She notes that in some societies teachers are regarded as guardians of a sacred body of knowledge, who are expected to preserve and 
promulgate cultural values through teaching and example. In Japan, she explains, they are also viewed as personal counselors to whom students may and do return for guidance, even many years after finishing their schooling.

The perception that teachers are responsible for the intellectual and moral formation of young people is also related to the survey question of whether learning is for the young or for people of all ages. In answering this question, four of the five informants in this study said that in Japan learning is primarily for the young, ranking it at the far end of that scale. The other informant felt that the situation was changing in Japan and it was becoming more acceptable for individuals who had finished their formal schooling to return to take classes as adults. None of the businessmen thought it was reasonable, however, for many Japanese to consider that option, since they felt they were too overburdened with work to have any extra time for non-workrelated study. In Aki's words, "there is not much opportunity for adults to study because there are so many works."

The question of whether learning is seen as a goal for just the young or as something to be pursued by individuals of all ages is an area that Hofstede relates to concepts of individualism and collectivism. He posits that individuals from collectivist cultures would agree that learning is for the young, with adults not accepting or having access to the student role. On this point, the general perception of this group of informants seemed to be that Japanese society looked upon learning as something for young people, a perception that was in line with Hofstede's prediction about the attitudes of collectivist societies toward learning.

Other experiences in learning the value of group cooperation were identified by Aki, who described how his teachers would use stories from the 
news to "teach the importance of harmony," or what he noted is called wa in Japanese. They would relate a news event and then explain what was important or useful to be learned from the event as it applied to the concept of harmony, because, as he learned, "To keep doing a good job, we must harmonize. Everything is harmony." Expanding on that theme, he stated, "In Japan we do work in team. We can't work by ourselves." Relating this to the workplace, he also noted that, "To keep up with doing a good job in a Japanese company, we must harmonize. If worker does not think about harmony, after he will be expelled from company."

Again, the perception seemed to be that not working as part of the group, but working instead for one's private goals, would lead to isolation. The opposite, working cooperatively toward collectively defined ends would insure that each group member simultaneously satisfied his individual needs and secured his private welfare while promoting the general aims of the larger group. Going out on one's own would be dangerous and foolish, threatening to destroy the harmony of the group. Individuals in collectivist societies would tend to work for the group's goals instead of their own goals. Dore (1973) has termed the notion that members of the group cooperate in their efforts toward collective goals, "corporatism", wherein each individual successfully maintains his personal autonomy through his group efforts. In a collectivist society such as this, the group identity appears to precede the individual identity, not actually preclude it.

In Hofstede's tables of differences in teacher/student interactions, the concept of harmony in learning situations is associated with membership in collectivist societies while the idea of open disagreement in learning situations is associated with individualist societies. Support for Hofstede's contention was 
evident with each of the businessmen in this study indicating that maintaining harmony in the classroom was far more valuable than disagreeing with the teacher. This notion was also closely related to the participants' ideas about order and creativity and will be discussed at length in the section relating those concepts to language learning.

Another aspect of Japanese education that seems to reinforce the perception of the primacy of the group over that of the individual is the emphasis on traditional ideas as opposed to innovative ones. Each of the respondents in this study emphasized that education in Japan favors the traditional over the "new", including the kinds of subjects that are studied and the methods used to teach them. Aki explained that the content of Japanese courses is carefully controlled by "strict guidelines." He supported his statement by explaining that those guidelines come from the government, and "according to those guidelines, the teacher teaches." To ignore those guidelines, he maintained, would be disastrous, because students would not get the preparation they needed to pass the entrance examinations for high schools and universities.

Shido reiterated Aki's claims by stating that, "Teachers focus on something that they're in the entrance examinations for the university. So the teacher does not teach us something that they are not on the examination. So the teacher hardly takes a new material about subject."

Hiro, Shido's co-worker, further developed this idea by explaining that, "The system has set up the line. Then the teachers try to keep that. Teachers don't try to teach new things from other systems." He offered a possible side effect of such activity: the Japanese fascination for new products and ideas from abroad. His rationale was, "Maybe Japanese characteristic is that people 
are so interested in new things because they don't learn a lot of new things at school."

Whether or not the tendency to follow a strict set of curricular guidelines is in fact a reason for Japan's interest in novel products does not directly concern this study; nevertheless, the participants' comments do seem to indicate that there is a strong link between maintaining traditional course content and teaching methods in the Japanese school system and the goal of insuring that students are adequately prepared to take the examinations for secondary and post-secondary study. As a result, these businessmen view the educational process in their home country as being very traditional with little time for or emphasis on what they consider to be "new".

The tendency to value "whatever is rooted in tradition" above "whatever is 'new'" is another area that identifies collectivist cultures, according to Hofstede (1986, p. 312). The responses of these five individuals to Nelson's survey question about the value placed on traditional versus new ideas in education appear to support the claim that Japanese culture is indeed a collectivist one. They also seem to reinforce the concept that the Japanese educational system reinforces the group identity by providing students with the necessary and nearly identical tools needed to progress from one subgroup to the next.

Another question which seemed to deal with the maintenance of group norms and behavior asked whether teachers openly praised students in the classroom. There was some disagreement on whether teachers did say positive things about individual students in front of the group, with Osama indicating that it depended on the individual teacher, Aki stating that it was a common practice, and the other three maintaining that it was unusual behavior. 
Toro used the common expression about pounding down the nail that sticks up to explain his position: "For most teacher, Japanese style is, 'The nail appears, hit.' This very normally in Japanese." In developing this idea, he noted that what Japanese students and teachers valued was an individual that had "good character", not one who tried to be different. He further stated that Japanese students and teachers admired the individual who "Works for the group." In other words, open praise and recognition are not as important as acknowledgement of worth to the group.

According to Hiro, the use of open praise by teachers in the classroom would sound suspect to the students because, he claimed, "Most Japanese hesitate to say 'Thank you' or 'Great ' or something like that ... basically because if someone did a good job . . . anybody understands he did good job." All that was needed, he asserted, was, "just smile". That would indicate whether someone had done well. He illustrated his position with a description of how he felt during an ESL class at another American university. When confronted with a question to which there were many possible answers, he chose the wrong one. The American teacher's reaction was to say, "Nice try. Good Guess". For him, it was unusual for a teacher to acknowledge a mistake with recognition of the value of his trying. In his past experiences in Japanese schools, he noted, "The Japanese don't say that. If it is incorrect, it is incorrect." In fact, he maintained that such a remark from a teacher would be perceived as "insincere, not real" to the students, who would all know that a mistake had been made and might ridicule the erring student. This seems to be an important concept for teachers to consider when praising students' efforts. While such praise might be intended as a means of acknowledging and reinforcing students' willingness to take risks and volunteer answers, it may be perceived as insincere or 
superficial praise that is in fact more embarrassing and alienating for the student than it is reassuring.

For Shido, the idea of a teacher singling out one student for praise in front of the group was also quite unacceptable. He stated that such behavior was not appreciated by students: "The students don't want that. It is uncomfortable the students have individual rank." He added that he would feel a good deal of discomfort with being praised in front of the class, stating, "It feel like, feel not comfortable. I feel like not equality." He explained that teachers offer positive reinforcement through grades instead of singling out students for praise in the classroom. The grades, he indicated, were sufficient recognition and impetus for students, who he maintained would rather be "advised by the teacher individually, not openly." He also related how this concept applied to family life as well, indicating that when one of his children does something that deserves praise, he makes a point of recognizing something positive about his other child as well. He indicated that it was important that one child did not feel left out or slighted: "If Japanese parents praise their children, they praise both, both the children." In that way, he indicated, even the small sibling group would maintain its cohesiveness.

For some of the executives surveyed, open praise was acceptable behavior and did not bother them. For others, however, it seemed to violate the proscription against singling out individuals from the group, thus causing them to stand out and making them vulnerable to possible scorn from other group members. According to Hofstede, the use of open praise in the classroom is a characteristic of masculine societies, a designation which Japanese society ranked highest in. The fact that these five businessmen did not agree on this difference may mean a number of things, among which are: that this is not an 
entirely accurate measure of "masculinity" within cultures; that Japanese culture is not so masculine as data from Hofstede's surveys indicated, possibly in the process of changing; or that these individuals do not represent "typical" Japanese views in this area. Whatever the implications, it seems that the idea of open praise in the Japanese classroom may also be closely tied to perceptions of group identity and harmony, not just to ideas associated with masculinity.

Perhaps the most revealing questions in this survey process that related student perceptions of teacher/student interactions to group identity and behavior were the two asking whether individual students would speak up in class voluntarily or only when called upon by the teacher. The wording of the two items was slightly different, but the interpretations of and responses to them were the same. All of the respondents indicated that Japanese students seldom if ever speak up in class unless they are called upon directly by the teacher. Explanations varied as to why this is so.

Several of the businessmen indicated that Japanese students are by nature "shy". They claimed that this was part of their "personalities", and they could offer no further explanation. Hiro, however, put forth a theory that he seemed quite sure of, and which he related directly to his perceptions of group responsibilities and concerns. Using himself as an example, he remarked, "I don't want to disturb the class, the pace of the class. And if I ask a question, the teacher has to make a lot of time to discuss with me. In this case the others don't matter." Asked to explain this further, Hiro added that, "It's based on the culture of Japan. You consider the other people first." He then went on to argue that what is often thought to be "shy" behavior by Japanese speakers may in fact be "considerate behavior", noting that many Japanese students require 
"impact" before they will speak up in a large classroom situation. To him, "impact" meant being asked to speak by someone else. Another of his comments illustrates this idea: "Japanese usually don't speak from oneself first. They need an impact. They like someone to ask first."

Aki expressed similar perceptions about why Japanese students don't interrupt to ask questions, stating that, "Teaching time is precisely done on schedule with no delay or cancel." In his interpretation, when a student interrupts the flow of a teacher's lecture, this is an example of "disorder in the class." As such, it disturbs the harmony of the group, the wa. Since it is important that, "All students must blend in with other students," it is behavior that is frowned upon, behavior that can also lead to an individual being ridiculed and possibly excluded from the group. In fact, he noted, students who fail to place the group's concerns of their own would be "sent out", away from the group, and ultimately away from school.

The idea that reticence in speaking up and in asking questions in class is tied to perceptions of group priorities and approval seems quite important. If in fact this is the case, it may help to explain why Japanese students seldom volunteer comments in class without being called upon directly. It might also help to explain what is meant by the self-characterization of "shy" that so many Japanese use to describe themselves. While it most likely includes the fear of standing out from the rest of the group, it might also include the reluctance of students to take time away from the group in order to have individual questions answered. In a system which mandates that a specified amount of material must be learned in a limited period of time, there can be real pressure to avoid taking valuable time away from the group and endangering their chances of 
absorbing all they need in order to pass rigorous examinations by asking unsolicited questions or by speaking up when not called upon directly.

In summary, it appears that respect for group-related values and expectations may play a significant part in the form and frequency of classroom interactions for Japanese language learners. In a society which places a seemingly high value on interdependence among group members and group consensus, there is less need or support for individual initiative in expressing personal opinions in the classroom or in appropriating class time for individual concerns and questions. Individuals who fail to put the welfare of the group before that of themselves are likely to be the recipients of criticism and even exclusion from the group. In the school environment, that can mean adherence to a set curriculum which emphasizes cooperative values as opposed to individualized attention and goals. Such a course of studies will also have a significant impact on other aspects of classroom interactions, including perceptions about the roles of creativity and order within the learning process.

\section{CREATIVITY VERSUS ORDER IN LANGUAGE LEARNING}

An idea current in many Western cultures is that the individual and society are two distinct and sometimes opposing entities. In this view, when the group is given precedence over the individual, the individual becomes subdued in these cultures, working like an automaton or a cog in an institutional wheel. One's creativity is buried or oppressed without a sense of autonomy. If and when one chooses to join a group, it is often in a contractual arrangement with well-defined protection for individual rights.

This is not the case in Japan, where one does not have to become independent of one's group in defiance of or in rebellion against society to 
maintain autonomy and creativity. In fact, the 'rugged individual' of some Western societies might be looked upon as a lonely, isolated individual in Japan, an outsider disregarding the preferred order of society. Group membership in Japanese society provides a sense of attachment to the group that is pleasant and desirable. In addition, the existence of well-defined group norms helps determine both the level and form of individual and group responsibilities. As a consequence, order is much less threatened, according to Rohlen (1989).

With positive assumptions about attachment to the group, there is also a sense of "connectedness" where, Rohlen contends, "emotional and instrumental issues are intertwined" (1989, p. 30). Emotional aspects include sensitivity to others and intimacy among group members. Instrumental issues involve attitudes toward and respect for authority, together with understanding of individual rank within the group and its implications in interpersonal negotiations. In this type of arrangement, order is maintained through give and take negotiations, and misbehavior by one individual becomes a concern of the whole group. Resolution of problems prompted by an individual's behavior will also bring the offender back into the group, where reattachment takes place, much as it does in the family, according to Rohlen.

The need for attachment to the group seems to be a strong priority in Japanese society, one that is closely related to the maintenance of order. Group sanctions toward disruptive behavior are so strong, that individuals face severe censure and even dismissal if they ignore the group's norms. The whole system ultimately rests on an assumption of human nature as embedded in closely-linked social ties. 
In the Japanese classroom, the need to maintain order seems especially strong. As noted earlier, students view the group's goal of digesting a large amount of information within a strictly allotted time frame to be of utmost importance. Behavior that inhibits progress toward that goal, then, is disruptive and subject to censure. Behavior which might be considered creative and positive in American classrooms is not necessarily viewed that way in the Japanese school system. Different views on what is more desirable became apparent during this study with discussions about the following survey items:

\section{TABLE ॥}

\section{PARTICIPANT RESPONSES ON SURVEY ITEMS - PART B}

Question number

11. Students feel more comfortable in structured, formal classrooms.

$$
A=8 \quad B=9
$$

14. "Order" is valued in the classroom.

$$
A=5 \quad B=1
$$

2. Emphasis on student-centered education (students make decisions about what happens in class).

$$
A=8 \quad B=10
$$

6. Students expect teacher to give them direction.

$$
A=2 \quad B=1
$$

13. It's okay to disagree with the teacher.

$$
A=9 \quad B=8
$$

12. Students compete with each other.

$$
A=5 \quad B=9 \quad C=8 \quad D=8 \quad E=2
$$
$A=$ Toro
$\mathrm{B}=$ Osama
$\mathrm{C}=\mathrm{Aki}$
$D=$ Shido
$E=$ Hiro $C=5 \quad D=3 \quad E=9$ classroom.

$D=1 \quad E=3$

$$
D=9 \quad E=10
$$
their own direction.
$D=1 \quad E=3$

$\mathrm{D}=5 \quad \mathrm{E}=8$

vs. Students feel comfortable in unstructure

vs. "Creativity" is valued in the

Emphasis on teacher-centered education (teachers make decisions about what happens in class).

vs. Teacher expects students to find

vs. It's not okay to disagree with the teacher (harmony should be maintained).

vs. Students cooperate witheach other. 
One of the ways in which the respondents indicated that the Japanese school system emphasized the importance of order was in the physical layout of the classrooms. All of the businessmen noted that they were used to and more comfortable in classrooms that were arranged in a traditional lecture style, with the teacher's desk and blackboard in the front and student desks arranged in rows facing the front. For Toro, this style was "formal, very formal", and it helped to maintain a semblance of order in the classroom. To illustrate his point, Toro drew diagrams on the board of the typical Japanese classroom (lecture style) and of an American elementary classroom he had visited with one of his other ESL teachers. In the latter, the students sat at round tables that were placed throughout the room, an arrangement which he said facilitated discussion and movement for students and teacher. He noted that in the American classroom, "The structure is very informal." He also recalled that several of the students were sitting on the floor, and at one point, one of the young students even lay on the floor for a period of time. His reaction: "That is excessive."

Commenting on the diagram that his co-worker had drawn, Osama explained, "If I study in this room (pointing to the lecture style arrangement), it is easy for me to concentrate. But if I discuss, it is better the circle table." Describing his experiences, he continued, "In Japan, usually it is this style. It is very easy to concentrate, to study. It is easy to see the blackboard." For him, the traditional order of desks in rows was less distracting and more focused, with all students being forced to look at the teacher and the direction coming from that area of the room.

Another of the informants, Shido, echoed the comments of the other executives. For him, "Structured and formal class is better. That mean most of students like group activity, not individual, not creative." In other words, a 
classroom that seemed less-structured, or perhaps structured in an alternate format, was less conducive to maintaining group order and cohesiveness. It was preferable to sacrifice creativity to order in his view, indicating that differently-structured set-ups might be conducive to more creativity and less successful at maintaining order.

Additional support for structured, formal classrooms was voiced by Hiro, who explained that Japanese students feel more comfortable in that kind of learning environment because, "They have no experiences to discuss in class. Just I was given a lot of opinions or lectures or thoughts of the teacher." In other words, he equated a formal, structured setting with an accustomed style of learning, where teachers lectured and students took notes. This format did not include discussion of ideas, something he believed would make Japanese students feel uncomfortable. The perception again seems to be that a traditional, standardized arrangement of the physical classroom worked best when combined with a traditional lecture-style presentation of materials by the teacher. Order seems to be associated with the familiar, comfortable aspects of learning, while creativity seems to be linked to unpredictable, less comfortable areas of classroom interactions.

It was interesting, however, that when asked which style of classroom they preferred for language study, Toro, Osama, and Hiro all stated a clear preference for the less-formal arrangement. "It helps the communication," Osama remarked, when referring to the non-lecture style. For other kinds of classes, all maintained that the traditional style was more conductive to learning, partly because it contributed to the perceived orderly flow of information from the teacher to the learners. 
Order also seemed to be intimately tied to the ideas presented on group membership and responsibilities. Hiro made this connection by noting that, "In Japan the school has just formal class, just to give opinions from teachers to the students, and sometimes the teacher insists the opinions or questions; but the students maybe worry about whether or not students will be bothered the pace of class, or they disturb the other people." In his view, Japanese students tend to avoid making unsolicited remarks in the classroom for fear of disturbing the orderly progress of activities. Thus, the ideas of structure and formality in classroom situations seem to be interwoven among the fibers of respect for group identity and priorities.

According to Hofstede (1986), students' preference for structured, formal learning situations is an indication of high uncertainty avoidance, while preference for informal, unstructured ones indicates a low uncertainty avoidance rating. Uncertainty avoidance refers to the amount of anxiety or discomfort people feel for "unstructured, unclear, or unpredictable situations" ( $p$. 308). As a result of that uneasiness over uncertain conditions, Hofstede believes that people would prefer "strict codes of behavior and a belief in absolute truths" while exhibiting a "high level of pressure for social conformity and a strong inner urge to work hard" (1983a, p. 161). In addition, he notes that such cultures disapprove of "deviant ideas or behavior (1986, p. 308).

In the results of his studies, Hofstede (1980) had assigned Japan a score of 92 , indicating a very strong preference for more formal, structured learning environments. As a point of comparison, the United States received a score of 46 , theoretically indicating a lower preference for structure and formality in educational setting. 
Japan's score in this category places it well above the mean, and several comments by some of these informants further supported that ranking. They voiced a strong approval for what might be seen as strict codes of behavior and absolute truths. Shido, for example, insisted that regulations were extremely important in the Japanese classroom: "Teacher tells students to use the regulations even if regulation is ridiculous. Regulation is important." Later, he declared that the same attitude is present in the workplace, stating, "Rule is important, even if it is ridiculous."

A similar observation was made by Aki, who stated, "In Japan the rule must be obeyed by all students." When asked what the consequences were for not observing this dictate, he responded, "Scold or punished."

Further support for the importance of rules and order was voiced by Osama, who explained that rules were important for maintaining order. When students chose to disregard the rules, they were being "different, strange." Asked to explain this, he talked about dress codes and hair styles in schools, saying, "Different is not creative. Anybody can change his color of hair or clothes. That is not creative."

Following up on Osama's comments, Toro explained that students who chose to express their individuality by dressing differently or by changing their hair styles "in radical manner" were not viewed as being creative. Instead, they were seen as disruptive to the preferred order of the classroom, and their behavior was seen as "strange, and not normal", the deviant characterization noted by Hofstede. In fact, Toro further described this type of behavior as "outlaw", the kind associated with "drop out students".

In contrast to strange or deviant behavior, cleverness was perceived as being creative by Toro. This was strongly supported by Osama, who noted that 
creative people expressed that quality through "other abilities." In his view, other abilities had nothing to do with just trying to be different. It was associated with being a leader in the group and thinking up creative projects for the whole group. This was the person that was "valued", not someone who was simply trying to stand out and be noticed.

Further discussion of perceptions about order and creativity in the classroom centered around the survey question that asked the participants to rank which of those two values was more important. Both Toro and Osama noted differences in ranking depending on the kinds of activities or subjects being evaluated. Toro mentioned that teachers appreciate and hope to see creativity in students, but he qualified this by saying that in their study of English, they were not encouraged to be creative. On homework assignments, for example, accuracy was more important than creativity: "In that case, they need correctly. It is not so good to appear the creativity. In that case, it's not good." This was the case, he maintained, when doing writing assignments. Students were required to carefully follow models that they had been given. They were neither expected nor encouraged to develop original ideas in their compositions. It was more important to demonstrate mastery of correct forms and conventions than to develop interesting content.

For Aki, there was no question as to whether order or creativity was more highly valued. He stated that order was the most important value. It "is most highly demand." As examples, he recalled how classes always began on time, "precisely", with the students standing and bowing to the teacher, and requesting to be taught.

To demonstrate the higher value placed on order, Shido used examples from the classroom of students following regulations, regardless of whether they 
were "ridiculous". His examples included rules about clothing, hair styles, and schedules. Even though he found those regulations to be "ridiculous", he conceded that they were necessary for maintaining proper academic order, because they helped students "concentrate on important things."

Relating the concepts of creativity and order to the workplace, Hiro noted that,"In the company, creativity is more important than order." In the business atmosphere, he claimed, $100 \%$ is average. The big issue is doing 120,130 , or $200 \%$ more. That's creativity." In other words, creativity means doing more than is expected or trying especially hard. The reward, he explained, is being promoted or given recognition such as he had received: "That is part of why I am here, why I am hired by my company." For him, it was giving a little (or a lot) more than the average, or as he so aptly put it: "Like cooking; you add some spices to make it more delicious."

In Hofstede's (1986) discussion of teacher and student interaction patterns, he includes preference for order in the classroom as an aspect of teacher-centered education, contrasting it with "initiative" as a part of studentcentered education. He related this perception of differences to the concept of power distance, proposing that societies with large power distance scores prefer teacher-centered approaches to education while those with lower scores opt for more student-centered methods. Likewise, he proposed that cultures with high scores in this category valued obedience in children and conformity in classroom situations, with consensus as the favored means of conflict resolution. In the individual country rankings, Japan scored slightly above the mean with 54 .

In the survey used in this study, however, creativity appeared as the value that was in contrast to order. Thus, there may be some question as to 
whether this survey question fits accurately within Hofstede's power distance category. The responses by the executives in this study, however, seem to indicate that order was far more valued than creativity in their educational experiences and that conformity in classroom procedures was expected and desired. In addition, consensus was repeatedly suggested as the preferred form of conflict resolution, a process they deemed essential and "natural" in both classrooms and business settings.

With reference to whether emphasis was on student-centered or teachercentered education in the Japanese school system, the five businessmen were unanimous in confirming that a teacher-centered approach was what they had experienced during their school days. Each indicated that the teacher was responsible for selecting, explaining, and directing all phases of a typical lesson. The first experiences that any of them remembered in which they had a voice in the process was during their ESL studies in this country. As with other issues, they acknowledged that a student-centered approach sounded interesting, but they quickly added that they were more comfortable with a teacher-centered approach.

Closely related to these concepts was the survey question asking whether students expected the teacher to give them direction or whether the teacher expected students to find their own direction. Both Osama and Aki mentioned that the system was changing in Japan, and that students were being given more responsibility for choosing their direction. Neither, however, could give an example to illustrate the changes.

An interesting observation was made by Shido regarding this point. He noted that ESL teachers in the United States tended to take Japanese experiences and preferences into consideration when directing classes. As he 
stated, "I think our teachers think about the Japanese culture, so consciously give us direction." In other words, he thought that his ESL teachers were aware of the educational system that most Japanese had come from, and they were willing to offer those students more direction than normal to make those students feel comfortable.

For Hiro, the answer to this question also concerned the membership and direction of the group. While he recognized that most classroom activities had been teacher-centered, he also noted that at times students were expected to work together as a group to plan activities. In those cases, mostly having to do with non-academic activities such as sports or school outings, decisions were made through group consensus, after a director or chairman had been chosen by the group. The leader was chosen through majority vote, based on "recognition of natural leader(ship) quality". He explained that the, "Group just recognizes the leader" after the teacher gives directions to work as a group. Nevertheless, there is still a strong dependency on the teacher's direction, since, as he noted, "Students are so comfortable because they don't need to worry about their way by themselves, because teachers can decide their way which is better."

In a discussion of the role of the group in promoting social order, Rohlen (1989) observes that in the Japanese educational system, teachers will regularly step back from the exercise of authority, choosing either to delegate the task of problem-solving to the group or to let disruptive incidents play themselves out. In so doing, teachers do not abdicate authority at all. Instead, he proposes, they merely avoid applying their authority to particular events. In this way, the interaction of the group becomes pivotal in problem-solving and/or order preservation. Rohlen also notes that this is "a sign of confidence" that 
works "because authority is not weak or uncertain of its ultimate power to mobilize social forces" (p. 31). The result is that attachment to the group becomes a strong force in the maintenance of order, and it is an aspect of Japanese society that is carefully cultivated and nurtured.

Order as a primary value in classroom interactions is closely tied, then, to the idea of group harmony. The importance of maintaining harmony was earlier discussed with regard to the question of whether it was acceptable to disagree with the teacher in the classroom. As the informants noted, open disagreement was not viewed as acceptable behavior, largely because they interpreted it as an interruption in the smooth process of transmitting information from the teacher to the learners.

While it may seem that a society which places such a high premium on group consensus and harmony as Japan does would be very smooth-running and conflict-free, this is not necessarily the case. Lebra (1984) contends that it is an oversimplification to say that conflict and harmony are mutually exclusive concepts. She maintains that societies such as Japan that are very harmonyoriented are also very conflict-sensitive. Because so much emphasis is placed on interdependence, cooperation, solidarity, and harmony in Japanese groups, she believes that Japanese individuals are more likely to interfere with one another's actions. She posits that the regular attention given to the promotion of harmony within the group is what makes people more aware of conflicts with others and conflicts between their self-interests and their obligations. When individuals in such a society place personal goals before those of the group, they "will find the imperative of sociability and harmony oppressive" (p. 56). In short, the heightened awareness of one's responsibility to maintaining group 
order may actually work to intensify rather than mitigate potential conflicts in Japanese society, including classroom situations.

One of the possible results of this tension to resolve conflicts occurs in situations where students might wish to disagree or interrupt. At those times, they may display a public 'face' or character that is different from their private face representing actual feelings. These two faces are termed tatemae, the public face or behavior, and honne, the private feelings that may be masked to maintain smooth social relationships. According to Wagatsuma (1984), tatemae is "that which one can show or tell others," while honne is "that which one should or had better not show or tell others" (p. 376).

Tatemae becomes the expression of one's commitment to or compliance with the social norms, such as not interrupting a class presentation with a question. Honne is more the expression of one's feelings about maintaining those norms, perhaps frustration, impatience, or anger. This is not to imply that Japanese students deny those feelings, but rather that they learn to accept such feelings as the natural consequences of social interactions, feelings which are not necessarily appropriate for public display.

While this approach may seem strange or duplicitous to Westerners who feel that outward behavior should mirror inner feelings, it does not seem to present a problem to Japanese students. As Wagatsuma (1984) indicates, the Japanese seem to have a greater tolerance for ambiguity and ambivalence, allowing them to accept both tatemae and honne without suffering from a sense of internal inconsistency (p. 377).

Notions of the public and private 'faces' surfaced in the discussions with the five businessmen when they responded to the question of whether students competed or cooperated with each other. Both Shido and Osama referred to 
differences in what Japanese students outwardly show and what they inwardly feel. According to Shido, "Students don't behave competitive, but inside their minds (they do)."

Osama expressed very similar perceptions: "Students inside compete, but surface cooperate." Explaining this further, he noted, "We don't prefer to quarrel, so peace, cooperate." To him, competition might be what one felt inside but cooperation was what one showed in respect for order within the group. It was important that what was outwardly visible was the commitment to cooperation.

When asked to describe how one knew what an individual was feeling inside, Shido, Osama, and Toro all insisted that one could tell by "inspiration". The term, "inspiration", was one that all three found difficult to define further. Toro ventured that it was one's "first impressions" of another person. His example was that when one individual met another for the first time, either or both could gauge the sincerity of the other by the person's greeting and smile. In his words, "We can tell an artistic smile from a real one." When asked to relate this to classroom experiences, all three individuals could recall no specific instances or examples to further illustrate that concept

According to Hofstede (1986), a culture's feelings about competitiveness and cooperation in the classroom are related to the masculine/feminine dimension of cross-cultural differences, with cultures ranking high on the masculine scale having a stronger preference for competitive styles of negotiation and cultures with a lower ranking preferring a more cooperative approach. While Japan ranked higher than any other country surveyed in this area, there seems to be some ambivalence in the choice of one characteristic over the other by these informants. In their views, it appears that both 
cooperation and competitiveness are compelling factors in classroom behavior. Their comments seemed to indicate that cooperation is extremely important in developing a sense of group identity and maintaining order in the classroom, while competitiveness is tied closely to individual motivation and feelings about present and future success. Likewise, success is often demonstrated in one's ability to pass the rigorous examinations that confront students preparing to enter secondary and post-secondary institutions.

In summary, both creativity and order seem to be intimately bound to the concepts of group identity, cooperation, and competitiveness. Creativity is evidenced in one's contributions to the group and its direction. Order is maintained by cooperating with the group in the achievement of its objectives. Cooperation is what is shown outwardly and nurtured in the group. Competitiveness is what lies below the surface, "inside their minds", as Shido remarked. It is also a powerful driving force in Japanese students' efforts in preparing for the examinations that determine so much of their future direction.

\section{THE ROLE OF EXAMINATIONS}

The third theme to thread its way its way through the fabric of these discussions was the role of examinations in the Japanese educational system. The importance of examinations in the lives of Japanese students is welldocumented in the media. Its notoriety includes the oft-heard designation of this process as juken jigoku, "examination hell". Recently, (September 12, 1992), National Public Radio presented a report on its Weekend Edition explaining that Japanese schools would be closing for one Saturday each month to allow children an opportunity to spend more time with their families and to play. The 
reporter noted, however, that the decision by the Japanese Education Ministry has not been well-received by many segments of Japanese society.

Several of the students interviewed in this report indicated that they would not use their free Saturday "to play". Instead, they planned to use the time to study harder for the upcoming exams that determined whether they were admitted to prestigious high schools and universities. A number of the parents complained because they were uncomfortable having their children at home while they were at work. As one mother explained, she felt more secure with her children being in school. Teachers complained because they recognized that they were going to lose valuable time with which they could help students prepare for the examinations. Instead of cutting the requirements of the curriculum, the new policy would simply result in the elimination of nonacademic activities such as field trips and community projects. The exam system was not being reformed, the teachers pointed out, they were simply losing valuable time that they needed to prepare students for it.

Although the topic of examinations was not one that was addressed directly by any of the survey questions in this study, it was one that surfaced repeatedly when the five executives talked about their backgrounds and experiences studying English. It also came up regularly when they answered the multiple choice questions in the second part of the survey about their perceptions of anxiety levels in the classroom and values in the workplace.

In discussing their experiences studying English in Japan, both Osama and Toro identified the entrance examination process as one of the key forces in shaping English teaching pedagogy in that country. They indicated that the primary focus in the teaching of English was on composition, grammar, and reading, the areas that they would be tested on in the entrance exams. As Toro 
stated, "Because English is one of the methods to enter the more high grade of school or university, then we learn composition or grammar. Then teacher doesn't think conversation is so important." To prepare students for the exams, he contended, "Most Japanese English teachers do same thing, by the guidebook. They have guidebook and they follow the book carefully." The result of this emphasis on non-communicative language skills, he claimed, was that "Most Japanese cannot speak so well, but Japanese very good at test of English."

Osama's evaluation of the situation was very similar. As he recalled, his language classes did not focus on developing skills that he might need in actual conversations. They concentrated instead on the repetition drills and completion exercises that would make him a better written test taker. In order to further prepare themselves for the exams, Osama noted, most Japanese students purchase a book called Study English to Enter the University, a compendium of test strategies and former test questions meant to give its readers an edge on the English exams. Study of this book often takes place in the jukus, cram schools, that students attend after their regular classes on weekends and in the evenings. It was a tool which many students carried with them as they passed from regular classes to those of their cram schools.

Aki voiced many of the same observations about the teaching of English, as did Shido and Hiro. According to Aki, there are so many things that Japanese students must learn in preparation for the entrance examinations that there is no time for them to work on elements of English that will not be on the exams, most notably oral communication skills.

Reiterating what Toro had said about the need for teachers to adhere to strict guidelines for teaching, Aki added that teachers have no choice but to 
teach a set amount of material in a way that best prepares students for the exams. The result, he offered, was that "Teachers seem, look . . not human, like machine." Asked to explain this further, he volunteered that, "There are a lot of things to teach, so teacher have to teach mechanically, and student must write all the words." While his description of his teachers was not particularly flattering, Aki did endorse their teaching approach for being "efficient" and "precise", attributes which he appreciated during his school days.

Shido's indictment of English teaching methods was not quite as severe as Aki's, but he did point out that, "Japanese English teacher cannot speak English fluently." Perhaps, for that reason, he ventured, "In Japan conversation class is just talking, not discussing. Conversation, not communication. About very easy talking." It was interesting to hear him make the distinction between language use as merely habit formation and language use for communication.

A contributing factor for the emphasis on language use for "just talking", he maintained, was, "We have not enough time to discuss about something in day." Thus studying ESL at an American university was quite a change for him, because they "talked about politics, business matters. I've never talked about this in Japan." He described the change in approach as "difficult and very interesting."

The time factor figured in Hiro's observations as well. He remembered that, "School has just formal class, just to give opinions from teacher to the students." As a consequence, "Students worry about whether or not they will bother the class pace if they disturb other people with opinions or questions." As indicated earlier, the fear of depriving other group members of valuable class time by interrupting with one's own concerns seems to be a controlling force in shaping classroom interactions. The demands involved in preparing for 
the entrance examinations obviously weigh heavily on both students and teachers in those situations, and for students like Hiro, the perception of his proper role is to listen attentively without jeopardizing other students' limited time for learning in the classroom.

From the comments of all the participants in this study, it seems quite clear that there is a common perception that the teaching of English in Japanese schools is heavily impacted by elements relating to educational guidelines, teacher preparation, and time constraints. Each of those factors is in turn shaped by the omnipresence of entrance examinations waiting on the educational horizon.

One of the most common ways of dealing with the impending examinations has already been mentioned, attendance at the cram schools, the jukus. In his book, Learning to Bow, Bruce Feiler (1991) documents his experiences teaching English in Japanese rural communities. He devotes an entire chapter to the prevailing influence of the juku system, explaining how it developed from a century-long tradition of preparing students for higher education. Where a person's rank, family, or class used to determine one's future in Japanese society, admission to the correct university has now supplanted that role. He points out that in order to enter an elite university, one must pass that school's difficult entrance examination. The rite of passage now begins in elementary schools, where young children also attend cram schools to prepare them for the examinations for the academically competitive high schools. Once in those high schools, he explains, the "examination hell" continues as students attend other cram schools preparing for prestigious universities. The lengthy and demanding process is necessary because 
graduation from a highly-ranked university virtually guarantees lifelong employment with a reputable company.

Feiler raises an interesting question in his book: Why is a system of cram schools necessary in a country like Japan which is famous for its educational system? He proposes several possible answers. One is that Japanese teachers need to spend a good deal of time "teaching 'warm' concepts like moral education, national pride, and group cooperation" (p. 187). As a result, they have less time to devote to more academic subject matters. Another reason he offers is that the Japanese school system does not group students according to ability, and little effort is made to account for individual differences. Consequently, a large number of students simply get left behind when they cannot keep up with the demanding pace of regular classes.

Still another answer which he suggests is that the government continues to stress the importance of discipline in both comportment and mental preparation, largely because of complaints from universities and companies about the growing lack of discipline among young people. Thus, it "continues to put children through 'examination hell' because the same powerful institutions claim that the tests are screening devices" (p.188).

A similar observation about the entrance exams is presented by Singleton (1991), who maintains that, "It is not the content of the entrance examinations but the intense experience of exam preparation that is believed to strengthen an individuals' character and moral fiber" (p. 122). Thus, "examination hell" is a process that is meant to not only increase a student's storehouse of knowledge but also to build moral character, what is often called gambaru, the ability to endure. 
The final reason that Feiler gives for the existence of the cram system is the understanding that Japanese university students are allowed to "play" while in college, and as a result, "corporations cannot rely on college transcripts as a gauge of ability." Instead, they choose employees based on the reputation of the university they attended, "thereby increasing the importance of the exams that the students had to pass in order to be admitted" (p. 188).

In this group of informants, all but one had attended at least one cram school. None of them expressed a good deal of admiration for the system, but all noted that it was a salient feature of the Japanese educational system at the present time, and none expected it to change dramatically in the near future. Hiro noted that the system was now somewhat self-perpetuating. Since almost all Japanese children were enrolled in cram schools, there were no opportunities for children to socialize with other children after schools or on weekends, unless they were in those same juku programs. In other words, if parents decided not to enroll their children in one of those schools, they would in essence be pulling them out of their respective groups, depriving them of the collective support and development they would later need as students and as adults in the workplace. In short, the entrance examination system has led to another layer of educational expectations that adds to the drain on students' time and energy.

Faced with the prospect of sitting for exams that effectively program much of their future lives, Japanese students are under extreme pressure to learn a great deal of information in a limited time. One of the results is that students regularly feel high levels of stress in the classroom. When surveyed with the question about how they often felt nervous or tense in Japanese classrooms, each of the executives responded with "always" or "usually". 
For Aki, the school classroom was extremely stressful. "I always feel nervous at school in my home country. It's because I feel very frequently tense," he stated. Relating it to specific causes, he noted that it was "because the examination and competition." Comparing it to his experiences in the United States, he recognized that the circumstances were very different. He said that he did not feel nervous in his ESL classes because, "One, there is no competition between students, and the second reason is the examination. I don't have to memorize the material. There's less stress." Still, he maintained that the stress was not all harmful. In his view, "It's hard to learn when there's no stress."

Shido expressed very similar feelings about stress and its relationship to the examination system. In his words, "In high school with reputation for the entrance examination, there is a lot of tension for most of the students. A lot of tension in the classroom." Asked whether that was true for him personally, he answered, "l feel very nervous, a lot of tension." He diagnosed the reason for his tense demeanor as twofold: the need to study for examinations and the teachers' attitudes. The fear of not learning enough to pass the entrance exams left him ever vigilant and concerned. The strict discipline and harsh reprimands for incorrect answers by his teachers kept him quiet and reluctant to ask questions. The latter he viewed as a direct result of there not being enough time to get through all the required material each school day. It was "the reputation for the entrance examination" that he blamed for much of his nervous anxiety in the classroom.

For Hiro, the link between feeling nervous or tense and examinations was very direct. In his recollection, "I was nervous . . . before the test. After the test, that's all." Asked to clarify this, he explained that those periods preceding 
examinations were the only times when he felt nervous in school, and his anxiety level peaked when preparing to take the entrance exams for the university.

While these individuals noted a high degree of nervousness in many of their classroom situations, it should be remembered that this was not necessarily viewed as a negative aspect of learning. The tension and nervousness are considered to be natural side effects of the stress being exerted on students. They are viewed as part of a larger picture, a scene in which the most admired students are those who can endure the best. They are also an important part of the pattern of socialization within the Japanese system of meritocracy that acknowledges and rewards individuals with outstanding university credentials.

In such a system, Shimahara (1991) points out,

Educational credentials are essential to gaining lucrative employment and determining individual mobility in a hierarchically structured workplace characterized by lifetime employment and a rigid seniority system. The coveted goal is to gain lifetime employment leading to status enhancement (pp. 131-32).

As a result of the benefits accruing from graduation from the elite universites, there is intense competition to pass those schools' entrance examinations. Teaching methods and curricula are therefore designed to prepare students for those examinations. Attention is given to the areas in which students will be tested, and for English skills, that is not communicative ability.

Although Japanese teaching goals and methods seem to be quite unlike those emphasized in many ESL classrooms in the United States, they obviously serve the purpose of reinforcing certain values, attitudes and behavioral 
patterns that are valued in Japanese society. Factors such as class size, time allotted for instruction, and teacher proficiency figure differently in decisions about what to teach and how to teach it. In turn, these differences affect classroom interaction patterns and students' perceptions of their own roles and that of their teachers in those interactions. 


\section{CHAPTER V}

\section{CONCLUSION}

\section{SUMMARY OF FINDINGS}

Results of the survey given to five Japanese businessmen to determine perceptions of student and teacher roles in the second language classroom indicate that there are certain assumptions that seem to be culturally relative. While the findings are not necessarily generalizable to a wider population than that of the individual respondents, they do seem to support aspects of Hofstede's (1986) hypothesis about there being differences in interaction patterns in the classroom that are related to his Four-Dimensional Model of Cultural Differences among societies.

The survey items generated from Hofstede's tables of differences in teacher/student and student/student interactions (1986) offer a possible framework for a qualitative explication of factors influencing interpersonal relationships in the English as a Second Language environment. The paradigm for this qualitative study provides a useful tool in the investigation of behaviors and attitudes in the second language classroom, and in so doing, it also lends credence to Hofstede's general contention that there are certain role patterns in educational settings that are "not only . . . the products of a society's culture, they are also the device par excellence by which that culture itself is transferred from one generation to the next" (1986, p. 302). The support derives from the responses of the five Japanese individuals in this study that identify 
highly-valued patterns of interaction that are deemed worthy of transference from one generation to the next. The comments also serve to enhance and expand upon the empirical findings of Hofstede used in developing his fourdimensional model of cultural differences and his tables of differences in classroom interactions.

This study has also suggested that there are certain themes that recur in the discussions about perceptions of student and teacher roles. Among those surfacing in this project with Japanese executives were views regarding individual versus group behavior and responsibilities in the classroom, the status of creativity and order in language learning, and the role of examinations in the Japanese educational system.

With regard to the first theme, perceptions of individual and group behavior and responsibilities, the comments of these five individuals reaffirmed the observations of numerous sociologists and anthropologists that Japan is a collectivist culture in which the concerns and goals of the group are given precedence over those of the individual. The prominence of this value is so interwoven throughout Japanese culture that it influences even the classroom interaction patterns of Japanese students. This was evidenced in the informants' responses indicating that Japanese students may be reluctant to ask questions in their classes for fear of usurping time from the group, time that is essential in absorbing as much material as possible in a limited amount of time. This in turn was linked to the standardized curriculum that reinforced the concept of Japanese students belonging to a larger group proceeding at the same rate toward the same general goal: admission to a prestigious university or technical school. 
Additional evidence for the primacy of the group over the individual included claims that Japanese students were reluctant to respond spontaneously in class for fear of making mistakes and appearing foolish in front of the group. Such behavior, the respondents indicated, would lead to possible censure and alienation from the group, results that were considered very upsetting and undesirable.

In related comments, the businessmen noted that Japanese students prefer to be recognized away from the group for both positive and negative achievements. Behavior that singles out students was viewed by these individuals as embarrassing and possibly disruptive. In a society that values harmony as strongly as the Japanese culture does, such treatment of students by teachers is viewed as counterproductive to the maintenance and strengthening of group identity. Instead, the regularly-promoted concept of teamwork was identified as the preferred norm, one that was reinforced through the teacher's use of special stories and activities in the classroom.

Standing out from the group, or not blending in, was regularly referred to as irregular or abnormal behavior by these informants. It was also related closely to the second theme that developed in the course of discussions on perceptions of student and teacher roles, the relative values of creativity and order in language learning. The statements by these individuals generally endorsed the belief that individualism as it is valued and perceived in Western societies is not the preferred norm of behavior in Japanese culture, including classroom environments. Instead, they maintained, one's ability to think of creative projects for the group and solutions to problems affecting more than just the individual were valued skills. Furthermore, creativity was not identified by any of the participants in this study as behavior that caused one to stand out 
from the group and be noticed. Rather, it was associated with giving more than 100 per cent, most notably to the group.

Additionally, most of these individuals felt that order is more highly valued than creativity in Japanese schools, and as such, their belief was that it strongly influences ideas regarding classroom organization and completion of homework assignments. According to these respondents, Japanese students tend to feel more secure in very structured classrooms, where explicit parameters help make learning easier. Interestingly, all the businessmen indicated that they preferred the more relaxed format of ESL classrooms in the United States for the study of English. What was repeatedly emphasized, however, was that the teaching of English in Japan involved different goals than it does in American ESL classrooms. They identified the primary goal in Japanese education to be the preparation of students for the rigorous admission exams of Japanese secondary schools and universities, exams which do not test students' communicative abilities in English. Consequently, they noted, students are neither taught nor expected to be able to use much more than basic speaking and listening skills.

In addition, all of the informants in this study remarked that teachercentered activities were much more common than student-centered ones in Japanese schools, in part it seemed, because those types of activities helped reinforce the concept of order. Maintaining order was also related to the emphasis placed on teaching conflict resolution in the group, a skill valued and taught in day-to-day classroom activities. Students learn to resolve conflicts within the group, as they develop and maintain interdependent roles based on trust and consensus. 
With regard to homework and classwork, there was general consensus that order and correctness were more highly valued than creativity in Japanese classrooms. The result in language learning is that students perfect the role of test-takers while ignoring that of communicators, as one of the individuals explained. Likewise, performance on writing assignments, as one of the businessmen remarked, was judged more severely for correctness than for originality. One of the participants also commented on the difference in classroom correction styles between his Japanese teachers and his American ESL instructors. The former, he maintained, demanded correctness at all times. The latter, he observed, were more willingly to acknowledge one's efforts, not just results, even when they produced incorrect responses. While noting the differences, the respondent was not saying that the non-Japanese approach was more helpful in developing preferred language skills. After all, correct meant correct to him. Likewise, the perception surfaced that voicing opinions about what was already general knowledge served no purpose. It was better to be quiet than to say what everyone already knew.

Throughout these discussions, the interviewees tended to portray the Japanese educational system as one that had as a goal fostering group identity and a sense of belonging above all else while enforcing order in design and implementation of the curriculum. One of the prevailing forces that they identified as instrumental in defining and supporting that role was the omnipresence of the examination system in Japanese education.

In addition to affecting the course content of their classes, the Japanese system of examinations also weighed heavily on the very structure of these participants' educational programs. All but one attended cram schools, which helped prepare them to pass the entrance examinations for secondary and 
post-secondary institutions. Each of these businessmen also reflected upon the tension and anguish brought on by the constant specter of examinations.

Several acknowledged that the pressures exerted by a system meant to teach a great deal in a limited time span influenced the way they responded in their classes. Not wanting to deprive others of valuable class time, they were reluctant to interrupt class proceedings with questions when they did not understand. Their role as students, when they did not grasp an idea or concept, was to just study harder on their own. What is more, concern about infringing on others' valuable time was coupled with fear of ridicule from both teachers and fellow students for "stupid questions", producing a reticence toward asking questions or positing individual opinions.

One of the results of the overwhelming pressure to do well on exams was the constant feeling of stress. All of these businessmen acknowledged that they felt that stress daily in the classroom. To some, however, this was not completely negative. They viewed it as a necessary evil, explaining that it was more difficult to learn in less stressful environments. Their role was to endure, because in the end, that would make them better individuals.

While each of the informants indicated that he felt the Japanese system of examinations needed reforming, none expressed optimism that significant changes would occur soon. Each readily admitted that it offered a way of determining one's membership in future groups, particularly since Japanese corporations continue to hire based upon one's admission to prestigious universities, not necessarily based on one's achievement in those universities. For that reason, none of the individuals in this study indicated that the system was without redeeming qualities. The benefit that some were able to identify 
was that the system forced them to assume a serious, dedicated role, one which helped insure their entrance into and success in their current occupations.

\section{LIMITATIONS OF THE STUDY}

The methods of analysis applied to this study, though limited in scope, were successful in determining perceptions of five Japanese businessmen regarding teacher and learner roles in the second language classroom. The responses of the participants in this study should be viewed as the voices of those five Japanese informants. They speak for a particular group of individuals, professional businessmen, who, having completed post-secondary education programs, were studying English abroad in recognition of past achievements and future requirements in their positions. As a result, their comments represent the views of those individuals and should not be generalized to all groups of Japanese students.

Initially, this study was designed to investigate the same areas of student perceptions over a longer period of time while using additional tools of research. Changes in the students' programs of study shortened the time that the informants were in the United States and available for interview sessions. The original design of the study was to interview and videotape students over a six-month period of time. When the program was amended to one of five-to-six weeks, the videotaping sessions were deleted. The prior intent had been to videotape students interacting in their ESL and regular university business classes, with follow-up discussions of the classroom exchanges recorded on videotape. When the students' program of studies was shortened, the regular university classes were also excluded. In addition, the number of students in the program was reduced dramatically. The result was very small classes of 
two or three students studying only English as a Second Language for a much shorter period of time than originally anticipated.

With the change in program design, a decision was made to forego the videotaping and use the limited time available for face-to-face interview sessions with the individual participants. While this allowed approximately five hours of audiotaped discussions with each businessman, it limited the data collection techniques to a single format: oral interviews. This process permitted a certain consistency in data gathering by ensuring that each respondent was exposed to the same questions by a single researcher; however, it did not permit the use of triangulation to obtain data from multiple sources in this study.

The size of the population interviewed was purposely limited to a small number. Nevertheless, those five interviewees constituted a group larger than the one originally projected for this study. Thus, while the length of the study was noticeably curtailed, the size of population studied was increased, allowing for potentially more reliable data.

The homogeneity of this group was both an asset and a detriment. With relatively similar backgrounds and experiences, these individuals were able to verify the comments of one another regarding views toward educational roles, since all had been part of very similar educational experiences. In that way, it worked to the benefit of this study by providing subjects with rather common points of reference to draw upon in answering the survey questions. It served as a detriment by limiting the variety of responses that might have come from a group of individuals with more diversity in age and training. While the techniques employed in this study served to elicit a wealth of data from these informants, they could likely be refined and expanded in future research with other positive results. 


\section{SUGGESTIONS FOR FURTHER RESEARCH}

Hofstede's Four-Dimensional Model of Cultural Differences (1980) offers a significant empirical base that could be exploited for a variety of research projects relating to perceptions of cultural differences among societies. In the area of teacher and student roles, one might consider looking more closely at how each of the four dimensions of the cultural model pertain to a specific society. That is, one could investigate a particular nationality using one or more of the dimensions such as individualism/collectivism in that particular culture. The findings might be compared to Hofstede's predictions and the findings of other researchers such as Nelson and Brown (forthcoming).

A related study focusing on an individual dimension of a particular culture might choose to use more than just the survey form developed by Nelson. It could include videotaped sessions of the learners' interactions in the classroom with follow-up questions to those individuals and/or their instructors about perceptions and recollections of what was transpiring during those classroom interchanges.

Another suggestion for additional research would be to expand or modify the survey form to include different items from Hofstede's (1986) tables of differences in classroom interaction patterns. For example, issues not covered in the individualism/collectivism dimension include topics such as saving face and students' expectations regarding their purposes for studying. These could be added to or substituted for items in Nelson's survey.

The possibility also exists to investigate the perceptions of a more divergent group of informants. Within the same culture, this might include individuals with differences in age, gender, educational background, and 
economic status. Among individuals from different cultures, there would likely be even more variety in the background experiences that might have a bearing on perceptions of educational roles.

An additional avenue for study of teacher/student roles might involve giving the survey to both students and teachers, thus allowing for more input from both sides of the desk. Or, the survey could be amended to focus more on teachers' perceptions of their own roles and those of their students. Again, this might be done within a single culture or expanded to include teachers and students from more than one culture.

A single theme, such as creativity versus order in language learning, might serve as yet another point of investigation among students of a single or a variety of cultures. As with the previous topic, this might be expanded to include teachers' views within those cultures, too.

One might also wish to investigate the language that is associated with the roles of teacher and student in various cultures, including the terminology used to describe the various responsibilities assigned to each position. These might also be discussed with references to currently popular or accepted teaching methodologies within those cultures.

Finally, one might survey returning EFL teachers to study their perceptions of teaching and learning roles abroad: how those views did and did not conform to their preconceived notions of what it would be like to teach overseas. This might include the use of diary studies to provide narrative descriptions of actual incidents and encounters.

While this study employed the survey form developed by one other researcher, it certainly did not exhaust the possibilities for its use in future studies of student and teacher roles in second language learning. 


\section{IMPLICATIONS AND RECOMMENDATIONS FOR TEACHING}

While the scope of this study was limited in both the number of participants and the time available for carrying out the interviews, there do seem to be significant implications resulting for ESL teachers working with Japanese students and members of other language groups.

Initially, the framework of this study proposes a useful tool for identifying and analyzing student accounts of experiences, perceptions, and assumptions. It uses a survey format derived from data in an extensive empirical study of cross-cultural differences among numerous societies. The items on that survey are based on findings from research conducted with a large sample of subjects and verified in the research by other investigators. As a research tool, the survey form provides a valuable instrument for use in examining classroom behavior patterns and in eliciting qualitative data to further elucidate aspects of the larger quantitative study.

Specifically, this study suggests that an underlying factor contributing to the interaction patterns of certain Japanese students in the second language classroom is the strong sense of identity with the group and the accompanying responsibilities that such membership implies. This includes a recognition of the limited time available in typical Japanese classrooms to ask questions and/or offer personal reactions to material presented. Such an awareness on the part of the student is likely to foster reticence in asking questions and reluctance in voicing personal interpretations or preferences, out of deference to the more important goal of allowing the entire group to learn as much as possible with a minimum of interruptions. 
Closely intertwined with this hypothesis is the idea that the fear of making a mistake and bringing ridicule and censure upon oneself may be so strong in this group of students that it constrains them from guessing or taking what would be considered normal risks in American classroom settings. Furthermore, it proposes that some of the reluctance to speak up may also be related to the fact that students fear what they are going to say is not important enough or is of such common knowledge already that their comments will appear superfluous and therefore deserving of ridicule.

Implications for language teaching seem rather obvious. Programs which stress fluency in speaking and listening will likely be uncomfortable locations for many Japanese students who have learned to withhold spontaneous verbal responses for fear of infringing on others' time and needs. In addition, teachers need to be aware of the possible reasons why Japanese students may more easily speak or write from the viewpoint of "We Japanese" than from the individualistic role promoted in American schools. Both positions must be viewed as culturally valid, reflecting the reality that each represents. In this respect, notions about one's role and that of others in classroom interchanges may seen as being heavily influenced by one's preconceptions about membership in the group and associated assumptions regarding one's responsibilities to that group.

In the same way, expectations about what constitutes creativity in the language classroom may need to be re-evaluated when dealing with Japanese students. Doing something different simply to be noticed or to separate oneself from the group may not seem to be a logical or appropriate role for those students to assume. This may also apply to areas such as writing and speaking, where the American educational system tends to place a high 
emphasis on independent work that incorporates original ideas and approaches. For students who have been taught that creativity means working to develop ideas which benefit the group as opposed to the individual, the new role assignments can be quite perplexing. Likewise, for students who have been taught that the value in completing homework assignments is tied to correctness and close adherence to models, there is likely to be a collision of cultural values when students are faced with tasks that offer few guidelines and high expectations for novel responses.

With respect to the teacher's role in the process of language learning, there may be some confusion when Japanese students are engaged in classroom activities with instructors who view their own roles as facilitators or guides rather than knowledge-givers or moral guardians. Teachers who are more used to and comfortable with student-centered activities promoting communicative language use may have to refine their methods to provide more models for language use employing more explicit directions than they are used to. This may entail limiting the number of activities with open-ended options for students.

Another recommendation might be for teachers to appoint leaders for small group discussions, until students are more familiar with their roles in those groups. A point to remember is that although Japanese students come from a society that places a high value on collectivist values including group membership and consensus-building, that does not mean that those students will automatically feel comfortable interacting in small groups in the second language classroom. In the new situation, they are likely to encounter very different expectations about their roles in the group and how those relate to the teacher's role in the classroom. 
Teachers might also want to be aware of how they recognize positive achievement by students. As some of the respondents in this study indicated, many Japanese students do not expect or feel comfortable in being singled out for praise in front of the class. Such behavior may create not only feelings of embarrassment on the part of the student being acknowledged, they may also lead to feelings of ridicule or condescension from group members who feel that work which is not exceptional is also not deserving of special commendation.

In a similar vein, providing a low-stress environment in which encouragement is liberally extended for risks taken may be a disconcerting and counterproductive approach for teachers to employ with Japanese students, if those students view it as an ingenuous attempt to make them feel successful. Such an approach may in fact produce the opposite effect, heightening tension and impeding rather than contributing to participation in classroom activities. Instead, a recognition of the goals of EFL teaching in Japan may prompt teachers to reconsider regularly offering supportive phrases to acknowledge incorrect responses from students. An approach which explains the differences in philosophies may help to prevent misunderstandings between teachers and students regarding the use of encouragement and praise.

Finally, it seems important to remember that a system that values and reinforces the acquisition of information, including language skills, for the purpose of passing demanding examinations can leave students at a disadvantage when those same students find themselves in classrooms with students and teachers who value other goals for language learning. Perceptions of one's own role and that of the teacher are likely to be quite different if the emphasis is not on completing a specific amount of work in a limited time frame. For language teachers who view their roles as facilitators in 
an on-going process of discovery and growth, it can be frustrating when their perceived role is different from the one that their students hold of them.

Nevertheless, the second language classroom, as the intersecting point of differing assumptions about teacher and student roles does not have to be a source of frustration or discouragement. It can be a studio where the craft of teaching does in fact bind together student and teacher in a fabric of intricate patterns of discovery and textures of understanding and intercultural communication. 


\section{REFERENCES}

Bailey, K. (1983). Competitiveness and anxiety in adult second learning:

Looking at and through the diary studies. In Seliger and Long (Eds.), Classroom oriented research in second lanquage acquisition. Rowley, MA: Newbury House.

Barnlund, D.C. (1975). Public and private self in Japan and the United States. Tokyo: Simul Press.

Becker, C.B. (1990). Higher education in Japan. International Journal of Intercultural Relations, 14, 425-447.

Benedict, R. (1934). Patterns of culture. Boston: Houghton-Mifflin.

Benedict, R. (1946). The chrysanthemum and the sword. Cleveland: Meridan Books.

Bennett, M.J. (1979). Overcoming the golden rule: Sympathy and empathy. In D. Nimmo (Ed.), Communication yearbook 3. New Brunswick, NJ: Transaction Books.

Brooks, N. (1968). Teaching culture in the foreign language classroom. Foreign Language Annals, 1, 204-207.

Brown, H.D. (1980). The optimal distance model of second language acquisition. TESOL Quarterly, 14: 157-164.

Brown, H.D. (1987). Principles of language learning and teaching: Second edition. Englewood Cliffs, NJ: Prentice-Hall.

Brown, J.D. (1988). Understanding research in second language learning. New York: Cambridge University Press.

Buck, E., Newton, B., \& Muramatsu, Y. (1984). Independence and obedience in the United States and Japan. International Jeurnal of Intercultural Relations, $\underline{8}, 279-300$.

Byram, M. (1989). Cultural studies in foreign language education. Clevedon: Multilingual Matters Ltd. 
Byrd, P. (1986). Barriers to cross-cultural communication in English-as-asecond-language programs in the United States. In P. Byrd (Ed.), Teaching across cultures in the university ESL program. Washington, DC: NAFSA.

Carrell, P. \& Eisterhold, J.C. (1983). Schema theory and ESL pedagogy. TESOL Quarterly, 17, 553-573.

Christison, M.A. \& Khranke, K.J. (1986). Student perceptions of academic language study. TESOL Quarterly, 20, 61-79.

Chronbach, L.J. \& Meehl, P.E. (1955). Construct validity in psychological tests. Psychological Bulletin, 52, 281-302.

Condon, J.C. \& Saito, M. (1974). Intercultural encounters with Japan: Communication, contact and conflict. Tokyo: Simul Press.

Condon, J.C. \& Yousef, F. (1975). An introduction to intercultural communication. New York: Macmillan.

de Saint-Exupery, A. (1967). Wind, sand and stars. New York: Harcourt, Brace \& World.

Doi, T. (1974). Some psychological themes in Japanese human relations. In J. C. Condon \& M. Saito (Eds.), Intercultural encounters with Japan. Tokyo: Simul Press.

Dore, R.P. (1973). British factory - Japanese factory: The origins of national diversity in industrial relations. Berkeley: University of California Press.

Enloe, W. \& Lewin, P. (1987). Issues of integration abroad and readjustment to Japan of Japanese returnees. International Journal of Intercultural Relations, 11, 223-248.

Feiler, B.S. (1991). Learning to bow. New York: Tichnor and Fields.

Fillmore, L.W. (1983). The language learner as an individual: Implications of research on individual differences for the ESL teacher. In M. A. Clarke \& J. Handscombe (Eds.), On TESOL '82. Washington, DC: TESOL.

Forgas, J. \& Bond, M. (1985). Cultural influences on the perceptions of interaction episodes. Personality and Social Psychology Bulletin, 11, 75-88.

Frey, L.R. (1991). Ethnography. In C.H. Botan, G. Friedman, \& G.L. Kreps (Eds.), Investigating communication: An introduction to research methods. Englewood Cliffs, NJ: Prentice-Hall. 
Furey, P.R. (1986). A framework for cross-cultural analysis of teaching methods. In P. Byrd (Ed.), Teaching across cultures in the university ESL program. Washington, DC: NAFSA.

Gorer, G. (1962). Themes in Japanese culture. In B.S. Silberman (Ed.), Japanese culture and character. Tucson: University of Arizona Press.

Gudykunst, W. \& Nishida, T. (1986). The influence of cultural variability on perceptions of communication behavior associated with relationship terms. Human Communication Research, 13, 147-166.

Gudykunst, W. \& Ting-Toomey, S. (1988). Culture and interpersonal communication. Newbury Park, CA: Sage.

Hall, E.T. (1976). Beyond culture. New York: Doubleday.

Hall, J.W. \& Beardsley, R.K. (1965). Twelve doors to Japan. New York: McGraw-Hill.

Hendry, J. (1987). Understanding Japanese society. London: Croom Helm.

Hofstede, G. (1980). Culture's consequences: International differences in work-related values. Beverly Hills: Sage

Hofstede, G. (1983a). Dimensions of national cultures in fifty countries and three regions. In J.B. Deregowski, S. Dzuirawiec, \& R. C. Annis (Eds.), Expiscations in cross-cultural psychology. Lisse, Netherlands: Swets \& Zeitlinger.

Hofstede, G. (1983b). Japanese work-related values in a global perspective. In H. Mannari \& H. Befu (Eds.), The challenge of Japan's internationalization. New York: Harper and Row.

Hofstede, G. (1986). Cultural differences in teaching and learning. International Journal of Intercultural Relations, 10, 301-320.

Hymes, D. (1961). Linguistic aspects of cross-cultural personality study. In B. Kaplan (Ed.), Studying personality cross-culturally. Evanston, IL: Row, Peterson.

Indrasuta, C. (1988). Narrative styles in the writing of Thai and American students. In A.C. Purves (Ed.), Writing across language and cultures: Issues in contrastive rhetoric. Beverly Hills: Sage.

Inkeles, A. \& Levinson, D. (1969). National character and sociocultural systems. In G. Lindzey \& E. Aronson (Eds.), Handbook of social psychology (Second edition, Vol. 4). Reading, MA: Addison-Wesley. 
Irving, K. (1984). Cross-cultural awareness and the English-as-a-secondlanguage classroom. theory into practice, 23, 138-143.

Ishida, I. (1984). Conflict and its accommodation: "Omote-ure" and "uchi-soto" relations. In E. Krauss, T. Rohlen, \& G. Steinhoff (Eds.), Conflict in Japan. Honolulu: University of Hawaii Press.

Johnson, P. (1981) Effects on reading comprehension of language complexity and cultural background of a text. TESOL Quarterly, 15, 169-181.

Johnson, P. (1982). Effects on reading comprehension of building background knowledge. TESOL Quarterly, 16, 503-516.

Kaplan, R.B. (1970). Cultural thought patterns in intercultural education. Language Learning, 16, 1-20.

Lebra, T.S. (1984). Nonconfrontational strategies for management of interpersonal conflicts. In E.S. Krauss, T.P. Rohlen, \& P.G. Steinhoff (Eds.), Conflict in Japan. Honolulu: $U$ of Hawaii Press.

Maurice, K. (1986). Cultural styles of thinking and speaking in the classroom. In P. Byrd (Ed.), Teaching across cultures in the university ESL program. Washington, DC: NAFSA.

Nelson, G. (1990). Proposal: Hofstede's four-dimensional model of cultural differences: An application to education.

Nakane, C. (1970). Japanese society. Berkeley: University of California.

Osterloh, K. (1980). Intercultural differences and communicative approaches to foreign-language teaching in the third world. Studies in Second Language Acquisition, 3, (1), 64-70.

Ouchi, W. (1981). Theory Z: How American business can meet the Japanese challenge. Reading, MA: Addison-Wesley.

Paulston, C.B. (1975). Linguistic and communicative competence. TESOL Quarterly, 8 , 347-362.

Peak, L. (1989) Learning to become part of the group: The Japanese child's transition to preschool life. Journal of Japanese Studies, 15, 93-124.

Pearson, E. (1988). Learner strategies and learner interviews. ELT Journal, $43,173-178$.

Reischauer, E.O. (1977). The Japanese. Cambridge, MA: Harvard University Press. 
Rohlen, T.P. (1989). Order in Japanese society. Journal of Japanese Studies, 15, 5-40.

Saville-Troike, M. (1976). Foundations for teaching English as a second language: Theory and method for multicultural education. Englewood Cliffs, NJ: Prentice-Hall.

Schumann, F. \& Schumann, J. (1977). Diary of a language learner: An introspective study of second language learning. In $\mathrm{H}$. Brown, C. Yorio, \& R. Crymes (Eds.), On TESOL '77. Washington, DC: TESOL.

Sellitz, C., Wrightsman, L.S., \& Cook, S.W. (1976). Research methods in social relations. New York: Holt, Rinehart \& Winston.

Shimahara, N.K. (1975). Social forces and schooling: An anthropological and sociological perspective. New York: David McKay.

Shimahara, N.K. (1978). Socialization for college entrance examinations in Japan. Cooperative Education, 14, 253-266.

Shimahara, N.K. (1991). Examination rituals and group life. In B. Finkelstein, A.E. Imamura, \& J.J. Tobin (Eds.), Transcending stereotypes: Discovering Japanese culture and education. Yarmouth, ME: Intercultural Press.

Spradley, J.P. (1979). The ethnographic interview. Orlando, FL: Holt, Rinehart \& Winston.

Stewart, E. (1971). American cultural patterns: A cross-cultural perspective. Pittsburgh: Regional Council for Educational Development.

Stewart, E.C. \& Bennett, M.J. (1991). American cultural patterns: A crosscultural perspective. Yarmouth, ME: Intercultural Press.

Sudweeks, S., Gudykunst, W.B., Ting-Toomey, S., \& Nishida, T. (1990). Developmental themes in Japanese-North American interpersonal relationships. Journal of International Relations, 14, 207-233.

Tinkham, T. (1989). Rote learning, attitudes and abilities: A comparison of Japanese and American students. TESOL Quarterly, 24, 695-698.

Triandis, H.C., Brislin, R., \& Hui, C.H. (1988). Cross-cultural training across the individualism-collectivisim divide. International Journal of International Relations, 12, 269-289.

Wagatsuma, H. (1984). Some cultural assumptions among the Japanese. Japan Quarterly, 31, 371-379. 
Whitehall, A.M. \& Takezawa, S. (1968). The other worker: A comparative study of industrial relations in the United States and Japan. Honolulu: EastWest Center Press.

Wolfson, N. (1989). Perspectives: Sociolinguistics and ESL. New York: Newbury House/Harper Row. 
APPENDIX A

CROSS-CULTURAL EDUCATION SURVEY 
Gayle Nelson

Georgia State University

\section{Cross-Cultural Education Survey: Part A}

What country are you from?

What is your native language?

How long have you been in the United States?

Are you an undergraduate student? yes no___ A graduate student? yes no.

Age Male Female

Have you taken this questionnaire before? yes no

This questionnaire is part of a research project investigating educational differences in various countries. Each item consists of 2 points of view and a scale from 1 to 10. Please circle the number that best represents education in your country.

For Example:

a student's failure

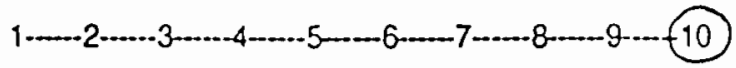

a student's failure is not too important is very serious

Please circle the answer that most accurately reflects your home country's educational practices Bnd bellefs. DO NOT ANSWER ABOUT THE UNITED STATES UNLESS THIS IS YOUR NATIVE COUNTRY.

emphasis on tradition, the way things have always

been done

emphasis on student-centered education

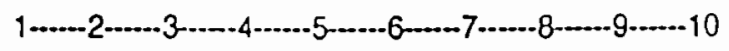
(students make decisions about what happens in class)

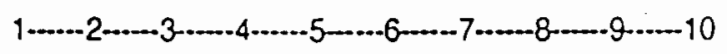

emphasis on "new"

emphasis on teacher-centered education (teachers make decisions about what happens in class)

in is okay for teachers to say "I don't know"

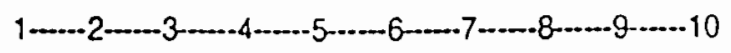

teachers ayoid openly praising (saying positive

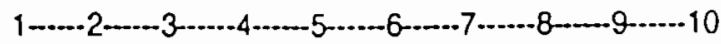
things about) students

learning is for the young

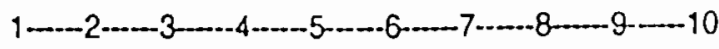
students expect teacher to give them direction

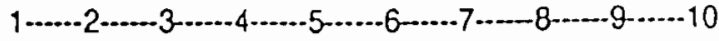

one is never too

teacher expects students to find their own direction old to learn teachers are expected to have all the answers

teachers openly praise (say positive things about) students 
good teachers

use academic

and formal

language

students admire intelligence in

teachers

students speak

in class only

when called on

by the teacher

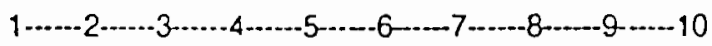

teachers are

never publicly

criticized (criticize-

to say what you don't

like about someone or

something)

students feel more

comfortable in

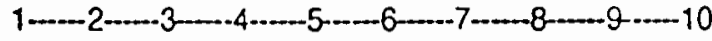

structured, formal

classrooms

students compete with each other

it's okay to

disagree with

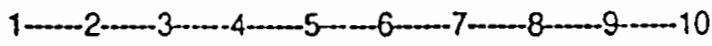

the teacher

"order" is valued in the classroom

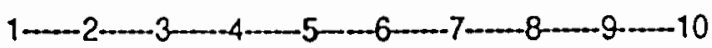

students want to blend in with

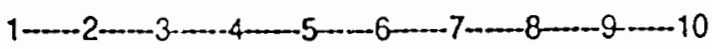
other students. to be part of the group

diploma certificates are important and $1 \cdots-2-\cdots-3-\cdots 4--\ldots-5--6--7-\cdots-8-\ldots 9 \cdots 10$ often put on walls and displayed

students may speak

in class when $1 \cdots \cdots 2 \cdots-3-4-\cdots-5-6-6-7-\cdots-8-9-10$ good teachers use ordinary and informal language

students admire friendliness in teachers

studems volunteer answers when the teacher asks a question

students can critlcize teachers students feel more comfortable in unstructured, informal classrooms

students cooperate with each other

it's not okay to disagree with the teacher (harmony should be maintained)

"creativity" is valued in the classroom

students want to be noticed, to be visible

diploma certificates have little value; they're just a piece of paper

students speak in class only when asked by the teacher 
teachers and students are allowed to show emotion and feelings

students choose courses because they are interested in them

teachers are expected to treat all students the same

older teachers are more respected than younger teachers

an excellent teacher is the cause of effective learning

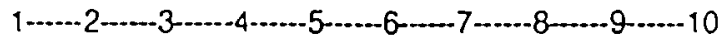
1
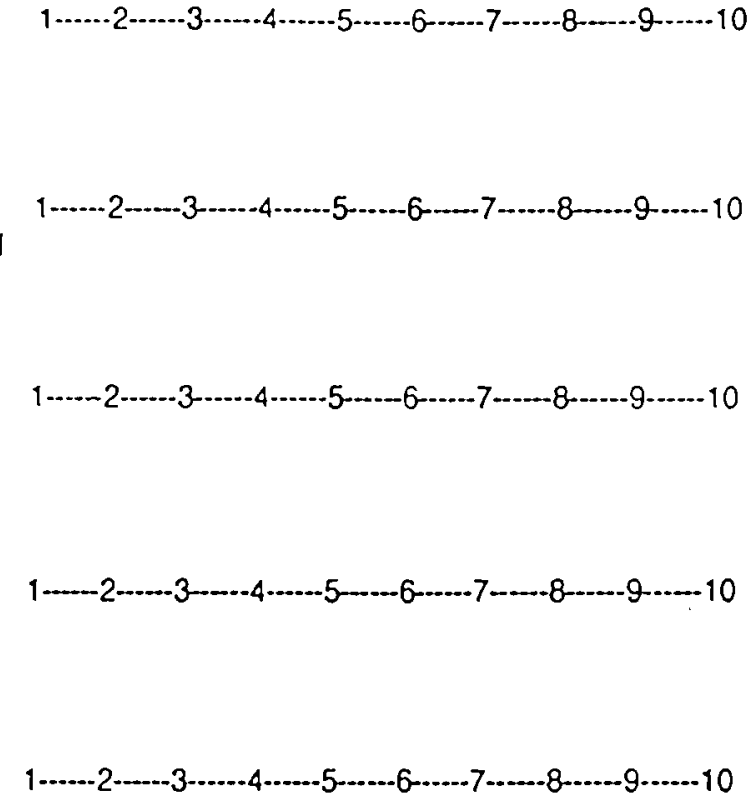

teachers and students are expected to hide or nos show emotions and feelings

students choose courses for career (job) reasons

teachers are expected to treat some students better than other students

younger teachers are better liked than older teachers

teacher-student interaction is the cause of effective learning

\section{Part B}

1. How frequently, in your experience, are students in your home country afraid to express disagreement with their teachers?
a. Very frequently
b. Frequently
c. Sometimes
d. Seldom
e. Very seldom

2. How often do you feel nervous or tense at school in your home country?
a. I always feel nervous at school in my home country
b. usually
c. sometimes
d. seldom
e. I never feel this way 
THE FOLLOWING QUESTIONS RELATE TO WORK:

3. Work or company rules should nef be broken--even if the employee thinks it is in the company's best interests.
a. strongly agree
b. agree
c. undecided
d. disagreo
e. strongly disagree

4. If you were to begin working for a company in your country, how long do you think you would work for that company?
a. two years at the most
b. from two to five years
c. more than five years (bun I will leave before I retire)
d. until I retire

5. Think of a perfect job. In choosing the perfect job. how important will it be to you to have sufficiem time left for your personal and family life?
a. of utmost importance (one of the most important things)
b. very important
c. of moderate importance
d. of little importance
e. of very little or no importance

6. In choosing the perfect job, how important will it be to you to have training oppontunities to improve your skills or learn new skills?
a. of utmost importance (one of the most important things)
b. very important
c. of moderate importance
d. of little importance
e. of very little or no importance

7. In choosing the perfect job. how important will it be to you to have a good working relationship with your direct superior?
a. of utmost importance (one of the most important things)
b. very important
c. of moderate importance
o. of little importance
e. of very little or no importance

8. In choosing the perfect job, how important will it be to you to have an opportunity for high earnings?
a. of utmost importance (one of the most important things)
b. very important
c. of moderate importance
d. of little importance
e. of very little or no importance 
APPENDIX B

INFORMED CONSENT FORM 


\section{INFORMED CONSENT}

I, , hereby agree to serve as a subject in the research project on Teacher'Student Roles in the ESL Classroom.

I understand the study involves completing a questionnaire, participating in oral interviews with the investigator, and viewing and discussing videotapes of classroom interactions. Those videotapes will be viewed only by the investigator, his assistant, and other subjects from the same class who are participating in the study. The videotapes will be erased at the completion of the study.

I understand that possible risks to me associated with this study are inconvenience because of regular interview scheduling and possible discomfort in discussing my feelings and views about my role as a second language learner.

It has been explained to me that the purpose of the study is to learn how international businessmen view their role in the second language classroom, and how that may affect their participation in classroom activities.

I may not receive any direct benefit from taking part in this study, but my participation may help to increase knowledge which may benefit others in the future.

John Armbrust has offered to answer any questions I may have about the study and what my part will be. I have been assured that all information I give will be kept confidential and that my identity and that of all other subjects will be known only by the principal investigator and his assistant.

I understand that I am free to withdraw from participation in this study at any time without it having any affect on my studies at Concordia College.

I have read and I understand the information on this page. I agree to participate in this study.

Date Signature

If you experience problems that are the result of your participation in this study, please contact the Chair of the Human Subjects Research Review Committee, Office of Grants and Contracts, 345 Cramer Hall, Portland State University, (503) 725-3417. 


\section{APPENDIX C}

INDIVIDUAL COUNTRY SCORES:

HOFESTEDE'S CROSS-CULTURAL DIFFERENCES 

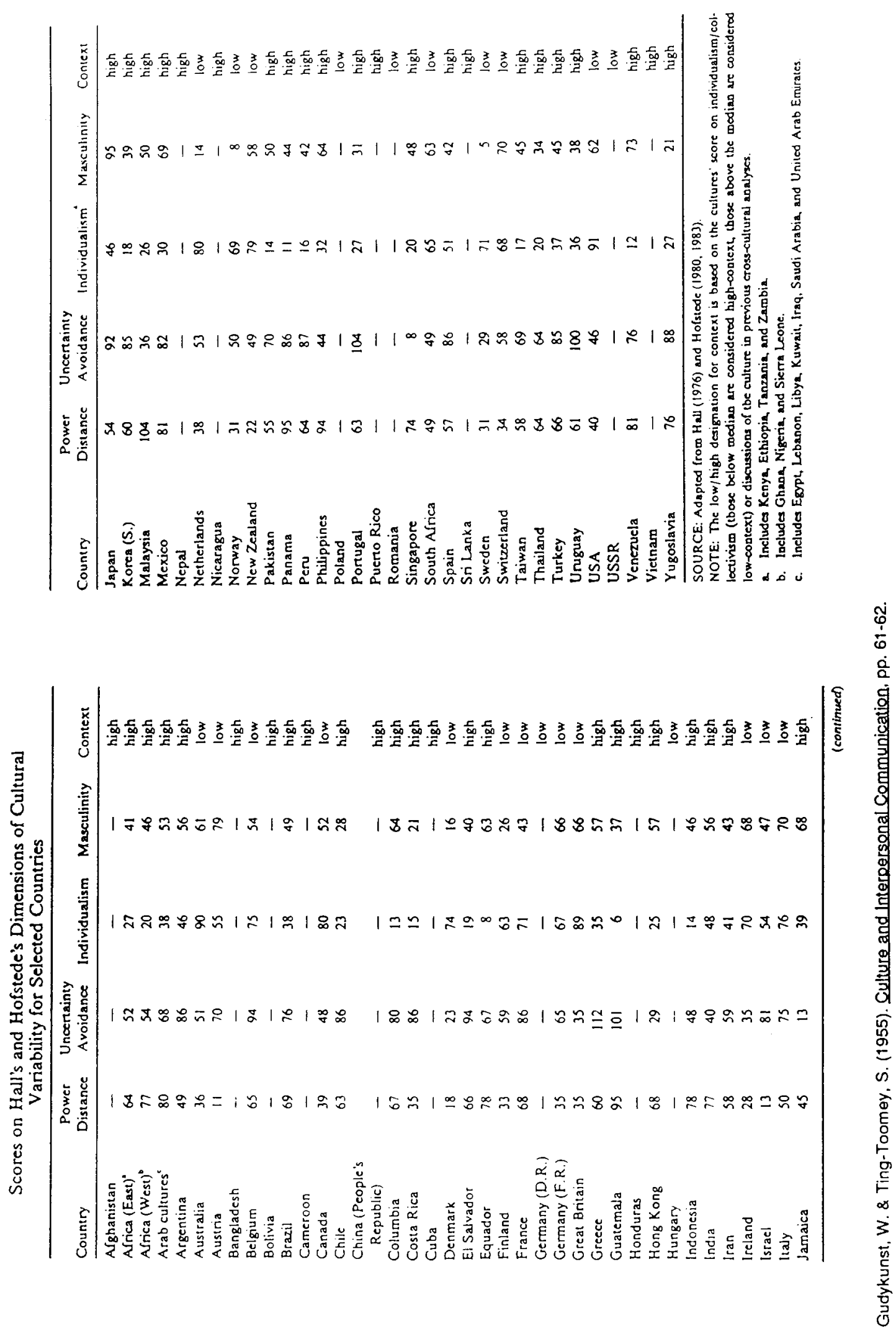